\title{
Macrophage-Based Combination Therapies as a New Strategy for Cancer Immunotherapy
}

\author{
Lin Tian ${ }^{a, b} \quad$ Anhua Lei ${ }^{a, b}$ Tianyu Tan ${ }^{a, b} \quad$ Mengmeng Zhu ${ }^{a, b} \quad$ Li Zhang $^{a, b}$ \\ Haibo Mou ${ }^{c}$ Jin Zhanga, b, d
}

aDepartment of Basic Medical Sciences, Center for Stem Cell and Regenerative Medicine, Zhejiang University School of Medicine, Hangzhou, China; 'b Institute of Hematology, Zhejiang University, Hangzhou, China; 'Department of Medical Oncology, Shulan (Hangzhou) Hospital Affiliated to Zhejiang Shuren University, Shulan International Medical College, Hangzhou, China; ' Zhejiang Laboratory for Systems \& Precision Medicine, Zhejiang University Medical Center, Hangzhou, China

\section{Keywords}

Macrophages - Phagocytosis checkpoints - Tumorassociated macrophages · Macrophage-based cell therapies

\begin{abstract}
Background: Cells of the immune system can inhibit tumor growth and progression; however, immune cells can also promote tumor cell growth, survival, and angiogenesis as a result of the immunosuppressive microenvironments. In the last decade, a growing number of new therapeutic strategies focused on reversing the immunosuppressive status of tumor microenvironments (TMEs), to reprogram the TME to be normal, and to further activate the antitumor functions of immune cells. Most of the "hot tumors" are encompassed with $\mathrm{M} 2$ macrophages promoting tumor growth, and the accumulation of $\mathrm{M} 2$ macrophages into tumor islets leads to poor prognosis in a wide variety of tumors. Summary: Therefore, how to uncover more immunosuppressive signals and to reverse the $\mathrm{M} 2$ tumor-associated macrophages (TAMs) to M1-type macrophages is essential for reversing the immunosuppressive state. Except for reeducation of TAMs in the cancer immunotherapy, macrophages as central effectors
\end{abstract}

karger@karger.com www.karger.com/kdd

Karger"
(C) 2021 The Author(s)

Published by S. Karger AG, Basel

This is an Open Access article licensed under the Creative Commons Attribution-NonCommercial-4.0 International License (CC BY-NC) (http://www.karger.com/Services/OpenAccessLicense), applicable to the online version of the article only. Usage and distribution for commercial purposes requires written permission. and regulators of the innate immune system have the capacity of phagocytosis and immune modulation in macrophagebased cell therapies. Key Messages: We review the current macrophage-based cell therapies that use genetic engineering to augment macrophage functionalities with antitumor activity for the application of novel genetically engineered immune cell therapeutics. A combination of TAM reeducation and macrophage-based cell strategy may bring us closer to achieving the original goals of curing cancer. In this review, we describe the characteristics, immune status, and tumor immunotherapy strategies of macrophages to provide clues and evidences for future macrophage-based immune cell therapies.

(c) 2021 The Author(s)
Published by S. Karger AG, Basel

\section{Introduction}

Macrophages, as the member of the mononuclear phagocytic system, can perform distinct functional phenotypes depending on tumor microenvironment (TME) cues. It is generally known that macrophages were de-

Lin Tian and Anhua Lei contributed equally to this work.
Correspondence to:

Lin Tian, tianlin602@163.com

Jin Zhang, zhgene@ zju.edu.cn 
fined into 2 polarized phenotypes, the classically activated M1 macrophages versus the alternatively activated M2 macrophages [1]. As macrophages reside in the TME, various signals activate extensively intracellular transcriptional cross talk in macrophages and lead to polarization of functions ranging from proinflammatory responses to inflammatory decomposition [2-4].

Macrophages in tumor do not develop directly from residential macrophages in tissues. They are recruited from monocytes in peripheral blood circulation [5]. A growing number of studies have suggested that the characteristics of TAMs are not the same as M2 macrophages $[6,7]$. The culture supernatant of the primary tumor can cause the phenotype and function of macrophages to shift to mixed M1/M2 polarized phenotypes from M1 or M2 macrophages completely [8]. In vitro, TAMs also can express interleukin-6 (a proinflammatory cytokine), whereas the expression of interleukin- $1 \beta$ (IL- $1 \beta$ ) and tumor necrosis factor-alpha (TNF- $\alpha$ ) is lower. Compared with M2 macrophages, the expression of CD163 and TGF- $\beta$ in TAMs is reduced by a 10th, which shows that TAMs may be a group of mixed macrophages inclined to M2 macrophages [9]. The phenotype of TAMs is significantly different in variant types of tumors and even in different parts of the same tumor. Therefore, according to the heterogeneity of the tumor cells, customized treatment strategies should be adopted for different cancers and patients.

In recent years, immune checkpoint inhibitors (ICIs) have shown good clinical efficacy in tumor immunotherapy. In 2011, the anticytotoxic T lymphocyte-associated protein 4 (CTLA-4) antibody ipilimumab for metastatic melanoma was approved by the US Food and Drug Administration as the first listed ICI [10]. In 2014, another ICI nivolumab was approved as the world's first publicly available programmed death-1 (PD-1) inhibitor [11-13]. In the following years, multiple ICIs were approved for several cancer species, including metastatic non-small cell lung cancer, gastric cancer, and liver cancer, which have substantially improved patient prognoses across multiple metastatic and treatment-refractory cancers [14-16]. The phagocytosis of macrophages is critical for bridging the innate and adaptive immunity activation in immunotherapy $[17,18]$. Normal tissues and cells have the intrinsic ability to avoid self-elimination by phagocytes through the expression of antiphagocytosis molecules. However, cancer cells cunningly exploit the antiphagocytosis mechanisms to evade immune-mediated eradication. The identification and therapeutic targeting of phagocytosis checkpoints in cancer might provide a promising avenue for the development of cancer immu- notherapies to eliminate tumor immune escape. Thus, targeting phagocytosis checkpoints of macrophages in the TME has been an issue of close attention for reversing the immunosuppressive status of TAMs (shown in Fig. 1).

In addition to exploit immune checkpoint mechanisms, another way to reverse the immunosuppressive status is genetically editing macrophages ex vivo and transplanting them for macrophage-based cell therapies [19-25]. Engineered macrophages in vitro injected into patients mobilize the activation of the TME, stimulating the activity of T cells in vivo and modulating the immunosuppressive state ultimately [26, 27]. During the early stages of the adoptive macrophage cell therapy, only a small number of macrophages were recruited to the tumor sites and might transform from an antitumor phenotype into the immunosuppressive status in the TME [26, 28-30]. Novel methods need to be developed to make adoptively transferred macrophages resistant to the TME and stay constitutively in an antitumor status.

\section{Development and Function of Macrophages in Tumor Progression}

Macrophages as innate immunocytes inhabit different tissues, with considerable heterogeneity. Despite the diverse residences, based on the polarization, macrophages have a series of general functions, including tissue remodeling, regulation of inflammation, induction of immunity, thrombosis, and various forms of endocytosis [31,32]. Macrophage polarization is constantly in flux at any point in an inflammatory process. IFN- $\gamma$ produced by Th 1 cells in combination with TNF- $\alpha$ or the activation of Toll-like receptors (TLRs) by bacterial cell wall components such as lipopolysaccharides (LPSs) can induce macrophages to become "classically activated" M1 macrophages. M1 macrophages in the TMEs can secrete proinflammatory mediators such as TNF- $\alpha$, IL-1 $\beta$, IL-12, IL-23, reactive oxygen, and nitrogen species and transform the immunosuppressive state of the TME via stimulating the cytotoxicity of $\mathrm{T}$ cells $[33,34]$. In contrast, macrophage polarization by activated Th2 cell-derived IL4 or IL13 produces an alternative set of cytokines and chemokines that oppose the repertoire of classically activated M1 macrophages, and these "alternatively activated" macrophages are designated as M2 macrophages [1, 35]. M2 macrophages generally express higher levels of scavenger receptors and proangiogenic factors [36, 37]. TAMs display an M2-like phenotype, including anti-inflammation, vascularization, and downregulated immunity [38]. 


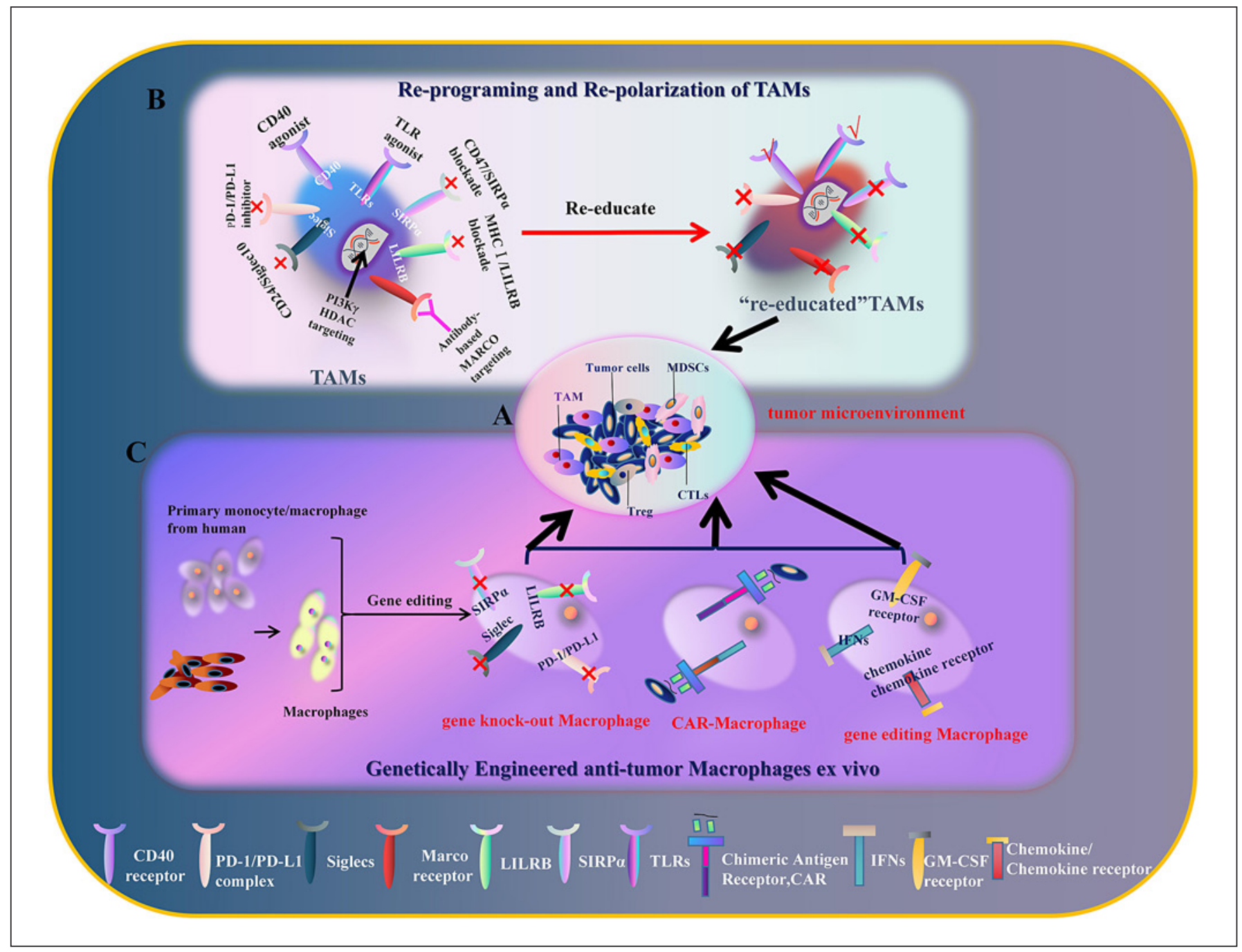

Fig. 1. Macrophage-based combination immunotherapies in cancer. A Macrophages are prominent in different tumor microenvironments of all types of malignancy. In solid tumors, macrophages can represent up to $50 \%$ of the mass, becoming the main immune population. B Reprogramming or repolarization of tumor-associated macrophages can improve the phagocytosis in certain types of cancer. $\mathbf{C}$ In addition to immunotherapeutic strategies to focus on reeducating immunosuppressive TAMs or enhancing macro- phage phagocytosis, another potential immunotherapeutic approach associated with macrophages is the application of genetic engineering to augment macrophage behaviors or endow new antitumor therapeutic functionalities. TAMs, tumor-associated macrophages; CAR, chimeric antigen receptors; $\mathrm{PD}$, programmed death, CSF, colony-stimulating factor; SIRP, signal regulatory protein; TLR, Toll-like receptor; HDAC, histone deacetylase.
Macrophages are prominent in different TMEs of all types of malignancy. In solid tumors, macrophages can represent up to $50 \%$ of the mass as the main immunocyte population [39]. Monocytes are recruited to the tumor tissues through blood vessels throughout tumor progression, promoting vascularization of primary tumor nodules, invasiveness, and the degree of malignancy of advanced tumors. Multiform cytokines and chemokines such as colony-stimulating factor-1 (CSF-1), the CC che- mokines, CCL2, CCL3, CCL4, CCL5, and CCL8, stromal cell-derived factor 1 (SDF-1/CXCL12), and vascular endothelial growth factor (VEGF) derived from tumors and cancer-associated fibroblasts can recruit macrophages to infiltrate tumors [40-42].

Generally, functions of TAMs in the TME can be described as follows: (1) the growth factors secreted by TAMs promote the proliferation and invasion of cancer cells, such as the epidermal growth factor (EGF) pro- 
duced by TAMs, and promote the invasion of cancer cells, and VEGF secreted by TAMs regulates cancer cell invasion and angiogenesis. Besides, CSF-1 generated by tumors can recruit macrophages infiltration so that the accumulation of EGF, VEGF, MMP-9, and TGF- $\beta$ produced by TAMs can further augment the invasion of cancer cells [43-45]. (2) TAMs can promote neoangiogenesis through secreting proangiogenic chemokines and proteolytic enzymes, such as MMPs and cathepsins, or expressing Tie-2 which can bind angiopoietins (Ang-1, Ang-2, etc.). Reconstitution of tumor-bearing Mmp9knockout (KO) mice by transplantation of wild-type, MMP-9-competent hematopoietic cells caused the reappearance of MMP-9-positive TAMs and restoration of tumor angiogenesis and metastasis [46, 47]. Tie ${ }^{\text {high }}$ TAMs can significantly promote angiogenesis of tumors, and upon depletion of Tie $\mathrm{Tigh}^{\text {Tigh }}$ TAM, angiogenesis and tumor growth can be inhibited such as glioma, pancreatic cancer, and breast cancer in mice $[48,49]$. (3) TAMs aggravate the immunosuppression of TME through the secretion of immunosuppressive mediators (TGF- $\beta$, IL-10, PGE2, etc.) to hamper the antitumor effect of the host immune system. Blocking IL-10, as well as other immunosuppressive cytokines present in the TME, may complement therapeutic strategies for antitumor immune responses [50]. Immunosuppressive molecules prevent the expression of MHC II on macrophages from antigen presentation to T cells. For instance, IL-10 can stimulate the expression of the E3 ubiquitin ligase March-I in activated macrophages, thereby downregulating MHC-II, CD86, and antigen presentation to $\mathrm{T}$ cells [51].

\section{Strategies to Target TAMs to Improve Antitumor Immune Responses}

In recent years, cancer immunotherapy has been focused on strengthening or improving the immune activation mechanism - developing various types of immunotherapy based on known immune molecular mechanisms, and promoting immune activation by controlling immune regulation to improve the effectiveness of antitumor immune responses. Exploiting immune cells with antitumor activity, such as adoptive T cells or natural killer (NK) cells, to replace immune cells that no longer have powerful functions in vivo, or to stimulate the activation of immune cells in vivo by tumor vaccine, have achieved the purpose of eliminating tumors [52].

However, cancer cells not only rely on "cancerous growth" to resist immune defense, but they also actively adopt various strategies to impede antitumor immunity - these strategies are collectively referred to as "immune evasion mechanisms." These tactics always destroy the intrinsic antitumor immunity and lead to loss of control of tumor growth. The immune evasion mechanisms continue to develop during cancer progression and become complicated in advanced cancer. Since the Food and Drug Administration approval of the CTLA-4 antibody ipilimumab for metastatic melanoma in 2011, ICIs have substantially improved patient prognoses across multiple metastatic and treatment-refractory cancers [10, 53-55]. So far, PD-1/L1 antibody therapy has shown efficacy outcomes of $>15$ cancer treatments, and the survival rates of melanoma and advanced non-small cell lung cancer have increased more than threefolds. However, the effective rate of PD-1 antibody in most patients with advanced tumors is only $20 \%$, and the drug resistance appears in the course of treatment. Therefore, it is crucial to focus on innate immune cell therapy and develop more effective phagocyte targets while searching for new adaptive immune checkpoints to improve the response rate of tumor immunotherapy [56-58].

\section{Phagocytosis Checkpoints of Macrophages as New Targets for Cancer Immunotherapy}

Cells of the myeloid lineage are the most abundant immune cells in the body originally, monocytes enter tumors through blood vessels throughout the life span of tumors, from early-stage tumor nodules that are beginning to vascularize to late-stage tumors that are invasive and metastatic, and macrophages, in particular, have a remarkable potential as mediators of anticancer therapies based on their robust ability to perform phagocytosis [59]. Macrophages gradually change from the initial M1 phagocytic state to M2 immunosuppressive state promoting the proliferation of tumor cells [60-62]. Macrophages possess multiple immunosuppressive receptors that initiate inhibitory phagocytosis signaling after binding to ligands at the surface of tumor cells $[61,63]$. The successful application of CD47 or PD1 antibody prompts us that targeting inhibitory signals of different tumors and exploring more immunosuppressive receptors in macrophages are essential to reverse the immunosuppressive state of the solid TME [59, 64-66].

At present, there are $>30$ sorts of inhibitory receptors in macrophage cells, which can be divided into 2 categories according to their structural characteristics. A class of immunoglobulin superfamily (IgSF) genes belonged to 
type I transmembrane proteins are mostly located in $19 \mathrm{q} 13$, and most of them contain immunoreceptor tyrosine-based inhibitory motif (ITIM), an immune receptor with (I/L/V) XYXX (L/V) sequence [67]. These receptors mainly include $\mathrm{Fc} \gamma \mathrm{RII}$, Ig-like transcripts, signal regulatory protein (SIRP), paired immunoglobulin-like receptor, killer receptors, CD22, and PD-1. The other class is the C-type lectins superfamily-coding gene, which is located at 12 p13 and belongs to type II transmembrane protein. It mainly includes the Ly49 family, NKG2 family, CD94, CD72, and dendritic cell (DC) immunoreceptor. These receptors are expressed in the form of disulfidebonded homodimers or heterodimers with extracellular recognition of carbohydrate-recognition domain whose ligand recognition processes are calcium-dependent. Since Fc $\gamma$ RIIb was reported as the first ITIM, ITIM-dependent inhibitory receptors and their respective ligands have been demonstrated to play a role in the control of various cell activities including NK cell responses (killer receptor-MHC class I ligands), phagocytosis mediated by macrophages (SIRPa-CD47), and adaptive T- and B-cell responses (CTLA-4-CD80/CD86 and PD-1-PD-L1/2) [67].

\section{The CD47-SIRP $\alpha$ Axis}

Identified in the late 1990s, SIRPa was found to be expressed on myeloid cells, with 3 extracellular Ig-like regions [68-70]. The cytoplasmic region contains 4 ITIM regions, which would be phosphorylated through extracellular domains connecting to ligands. The phosphorylated ITIM mediates the aggregation and activation of tyrosine phosphatase SHP1 and SHP2. Activated SHP1 and SHP2 in turn dephosphorylate some specific protein substrate to attenuate signaling induced by ITAM and eventually form negative regulation (shown in Fig. 2). CD47 is a ligand of SIRPa, which is an extensive transmembrane glycoprotein with an $\mathrm{N}$-terminal IgV-like region, 5 transmembrane regions, and a selectable intracellular binding region. A more recent study has confirmed the therapeutic efficacy of anti-CD47 monoclonal antibodies (mAbs) in eliminating small cell lung cancer xenograft in mice when used in combination with anti-CD56 mAbs [71]. In various xenograft tumor models, human CD47blocking mAbs were proven to have excellent efficacy against solid and hematological malignancies [72-74].

In 2014, the first agent targeting the CD47-SIRPa axis proceeded to clinical trials. So far, $>10$ anti-CD47 agents entered the clinical treatment, and clinical outcomes have shown the excellent data of partial agents, such as Hu5F9G4, TTI-621, CC90002, and ALX148 [75-78]. However,

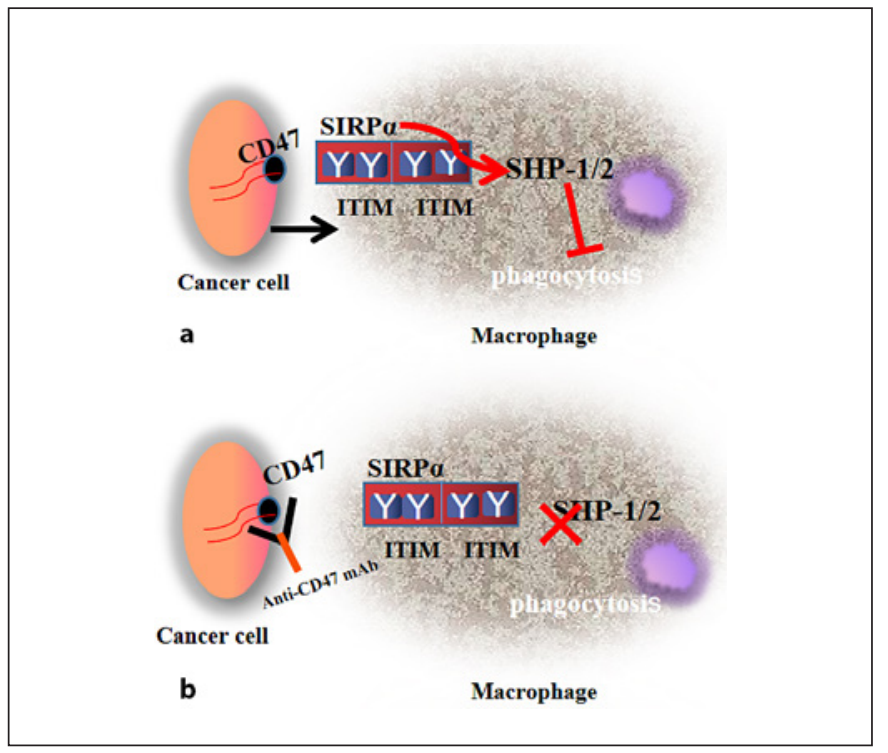

Fig. 2. The CD47-SIRPa axis. CD47 is highly expressed on multiple types of tumor cells. The phagocytosis is downregulated by the regulation of the inhibitory signal by the SHP-1 through which CD47 ligands bind to SIRPa, which is an inhibitory receptor expressed on macrophages. a When CD47 binds to SIRPa, the phosphorylated ITIM mediates the aggregation and activation of tyrosine phosphatase SHP1/SHP2, which inhibits phagocytosis via downstream mediators. b Blockade of the CD47/SIRPa axis using phagocytosis checkpoint strategies, such as antibodies, recombinant proteins, or engineered macrophages, attenuates the inhibitory signal to promote the phagocytosis of macrophages. SIRP, signal regulatory protein; ITIM, immunoreceptor tyrosine-based inhibitory motif; mAb, monoclonal antibody.

CD47 treatments may accidentally injure red blood cells, which also express CD47 and lead to anemia [79-81]. Due to the increase of "eat me" signals such as calmodulin (calreticulin) on the surface of aging red blood cells, the "eat me" signal exceeds the "don't eat me" signal of CD47, which promotes the phagocytosis of macrophages to the aging red blood cells. The classical CD47 mAb includes active domain $\mathrm{F}\left(\mathrm{ab}^{\prime}\right)_{2}$ that binds specifically to SIRP $\alpha$ and Fc segments that cause cytotoxic effects. The intense cytotoxicity of the Fc segment is bound to attack a large number of normal red blood cells, whereas the CD47SIRPa signaling pathway to exert biological effects without Fc segment is not sufficient to kill tumor cells $[82,83]$. In addition to modifying antibody molecules, adjusting the dosage and manner of treatment is important to reduce the incidence of anemia. The researchers developed a combination of "trigger dose" and "therapeutic dose" treatment regimens that incipient administration of short-term low-dose Hu5F9-G4 in combination with 
Table 1. Clinical trials investigating phagocytosis checkpoint blockade

\begin{tabular}{|c|c|c|c|c|c|c|}
\hline Drug & Target & Conditions & Strategy & Start date & Phase & NCT number \\
\hline $\mathrm{AO}-176$ & CD47 & $\begin{array}{l}\text { Lymphoma } \\
\text { AML } \\
\text { Solid tumor }\end{array}$ & Single agent & February 2019 & Phase 1 & NCT03834948 \\
\hline IBI187 & CD47 & Advanced malignancies & Single agent & January 2019 & Phase 1 & NCT03763149 \\
\hline SRF231 & CD47 & $\begin{array}{l}\text { AML } \\
\text { Solid tumor }\end{array}$ & Single agent or combination with rituximab & April 2018 & Phase 1 & NCT03512340 \\
\hline ALX148 & CD47 & $\begin{array}{l}\text { Metastatic cancer } \\
\text { Solid tumor } \\
\text { Non-Hodgkin lymphoma }\end{array}$ & $\begin{array}{l}\text { Single agent combination with } \\
\text { pembrolizumab or trastuzumab or tuximab }\end{array}$ & February 2017 & Phase 1 & NCT03013218 \\
\hline Hu5F9-G4 & CD47 & $\begin{array}{l}\text { Myelodysplastic syndromes } \\
\text { AML }\end{array}$ & Single agent or combined with azacitidine & September 2017 & Phase 1 & NCT03248479 \\
\hline Hu5F9-G4 & CD47 & Solid tumors & Single agent combined with cetuximab & November 2016 & Phase 1/2 & NCT02953782 \\
\hline TTI-621 & CD47 & $\begin{array}{l}\text { Hematological malignancies solid } \\
\text { tumor }\end{array}$ & $\begin{array}{l}\text { Single agent combined with rituximab or } \\
\text { nivolumab }\end{array}$ & January 2016 & Phase 1 & NCT02663518 \\
\hline CC-90002 & CD47 & $\begin{array}{l}\text { Leukemia, myeloid, and acute } \\
\text { myelodysplastic syndromes }\end{array}$ & Single agent & March 2016 & Phase 1 & NCT02641002 \\
\hline CC-90002 & CD47 & $\begin{array}{l}\text { Advanced solid and hematological } \\
\text { Malignancies }\end{array}$ & Single agent or combined with rituximab & March 2015 & Phase 1 & NCT02367196 \\
\hline NC318 & Siglec 15 & Solid tumors & Single agent & December2018 & Phase 1/2 & NCT03665285 \\
\hline JTX-8064 & LILRB2 & Solid tumors & $\begin{array}{l}\text { Single agent or combination with an anti- } \\
\text { PD-1/PD-L1 agent }\end{array}$ & Pre-IND & - & - \\
\hline $\begin{array}{l}\text { Anti-LILRB4 } \\
\text { antibody }\end{array}$ & LILRB4 & AML & Single agent & Pre-IND & - & - \\
\hline
\end{tabular}

PD, programmed death; $A M L$, acute myeloid leukemia.

rituximab, which triggered predictable and transient mild anemia, followed by the generation of new red blood cells, with the macroeffect of changing the overall age of red blood cells from older to younger, reducing the incidence of anemia [80].

\section{The MHC-I-LILRB Axis}

The promising clinical outcomes of the blockade of the CD47-SIRPa interaction confirm that targeting the immunosuppressive checkpoint of the CD47-SIRPa axis promotes the phagocytosis of macrophages [72, 73, 84]. Nevertheless, many cancer patients are irresponsive to the immunotherapeutic strategy for targeting CD47SIRPa due to the heterogenicity of tumors; therefore, more phagocytosis checkpoint inhibitors are developed for patients as much as possible [59] (shown in Table 1).

The LILRB is a group of type I transmembrane glycoproteins with extracellular Ig-like domains that bind ligands MHC-I, which is a class of inhibitory receptors expressed on myeloid cells (shown in Fig. 3). The receptors consisted of ITIM generate an immunosuppressive signal after tyrosine phosphorylation as a result of MHC-I of tumor cells and LILRB in macrophages interaction, leading to the blockade of macrophage phagocytosis. The expression of the common MHC class I component $\beta 2$ microglobulin $(\beta 2 \mathrm{M})$ by cancer cells directly protected them from phagocytosis. Thus, the treatment of blocking MHC class I molecules or LILRB1 can enhance the phagocytosis of macrophages $[85,86]$. In patients with tumors that have normal or high expression of MHC class I, agents directed at the MHC class I-LILRB1 axis might facilitate an antitumor immune response and could potentially act together with agents directed against CD47 or SIRPa.

Treatment with a blocking $\mathrm{mAb}$ to LILRB2 can reeducate TAM to improve the therapeutic effect of cancer immune therapies through the modulation of the TME. Researchers developed novel LILRB2-specific mAbs and found that a subset of LILRB2 antagonisms altered AKTdependent maturation of macrophages in response to macrophage CSF and enhanced NF- $\mathrm{KB}$ and STAT1 acti- 


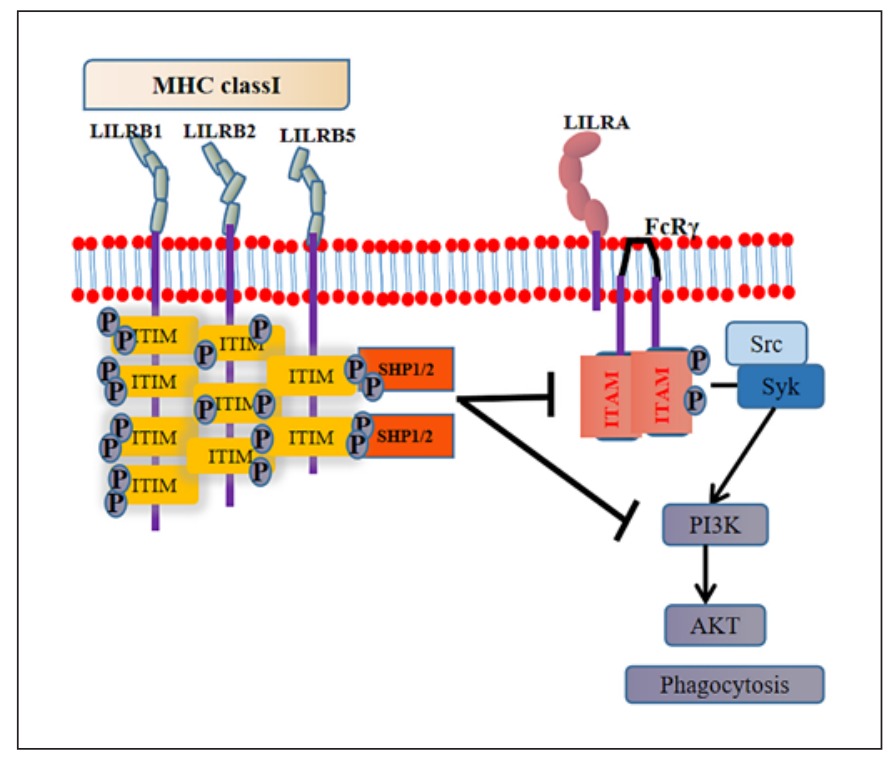

Fig. 3. The MHC-I-LILRB axis. The LILR family comprises a set of paired immunomodulatory receptors expressed among human myeloid and lymphocyte cell populations. The LILRB is a group of type I transmembrane glycoproteins with extracellular Ig-like domains that bind ligands MHC-I, which is a class of inhibitory receptors expressed on myeloid cells. The receptors consisted of ITIM generate an immunosuppressive signal after tyrosine phosphorylation as a result of MHC-I of tumor cells and LILRB in macrophage interaction, leading to the blockade of macrophage phagocytosis. LILR, leukocyte immunoglobulin-like receptor; ITIM, immunoreceptor tyrosine-based inhibitory motif.

vation in response to LPS/IFN- $\gamma$ stimuli [87]. Multiple immunosuppressive checkpoints exist in immune cells and have been found that the combined application of immune checkpoints can enhance the phagocytosis of macrophages $[88,89]$.

\section{Siglecs Axis}

Siglec is a lectin surface receptor molecule that binds sialic acid chain, consisting of a V-type amino-terminal immunoglobulin domain to regulate sialic acid recognition as well as several different immunoglobulin domains. According to its sequence similarity and evolutionary conservatism, Siglec is divided into 2 categories: the first includes $\mathrm{Sn}$ (sialic acid adhesin, siglec-1), CD22 (siglec-2), MAG (siglec-4), and siglec-15, and the second type is CD33-related Siglec, in which Siglec-5, -6, -7, -8, -9, -10, $-11,-14$, and -16 exist in the human body, and Siglec-E, -F, -G, and -H exist in rodent animals [90-92]. Siglecs are similar to other immunosuppressant receptors in various cells of the immune system, except for Siglec-4, which contain one or more ITIMs in the cytoplasmic domain

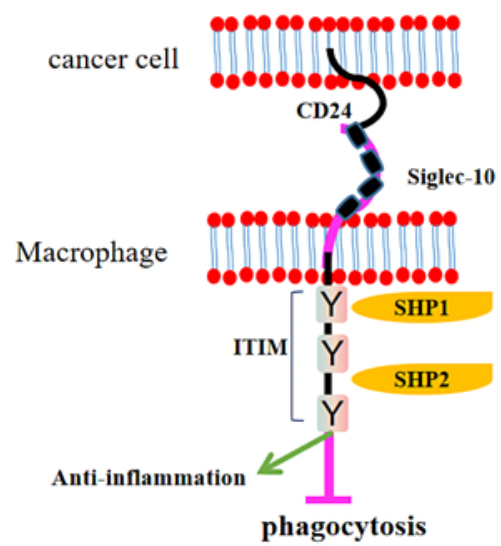

Fig. 4. The CD24/Siglec-10 axis. Siglec10 is similar to other immunosuppressant receptors in various cells of the immune system, which contains ITIMs in the cytoplasmic domain. Siglec-10 binds its ligand CD24 on cancer cells, and the intracellular ITIMs domains recruit the tyrosine phosphatases SHP-1 and SHP-2 and thus attenuates the phagocytosis of macrophages. Genetic ablation of CD24 or Siglec-10 by monoclonal antibodies, as well as blocking CD24-Siglec-10 interactions, can significantly enhance phagocytosis in all human tumors expressing CD24. ITIM, immunoreceptor tyrosine-based inhibitory motif.

[93]. After the surface sialylated sugar chain of the tumor cell binds to the macrophages, the intracellular ITIM domains recruit the tyrosine phosphatases SHP- 1 and SHP2 and thus regulate the cells of the innate and adaptive immune responses [94].

Earlier studies on Siglec focused on the expression of CD33 in monocytes, neutrophils, and myeloid progenitor cells. Gemtuzumab ozogamicin, an mAb specifically targeting CD33, was approved for clinical treatment of acute myeloid leukemia in 2002 [95]. At present, there are still many CD33-related tumor immunotherapies in the clinic. Recent studies have shown that other members of the Siglec family play a significant role in autoimmune diseases, inflammatory responses, and tumors by regulating innate and adaptive immune responses. Therefore, targeting Siglec family may become a new direction of tumor immunotherapy. Many tumors overexpress CD24, while TAMs expressed high levels of Siglec-10 [96]. Genetic ablation of CD24 or Siglec-10 by mAbs, as well as blocking CD24-Siglec-10 interactions, can significantly enhance phagocytosis in all human tumors expressing CD24 (shown in Fig. 4). 
Siglec- 15 is a member of the sialic acid-binding immunoglobulin-like lectin family (Siglec family) as a macrophage-associated T-cell suppressive molecule. It was suggested that Siglec-15 is closely related to the B7 gene family and may have the same immunomodulatory function as the member of the B7 family [97]. Gene ablation or antibody blockade of Siglec-15 can convert an immunesuppressive TME to an inflammatory site in some tumor models, which suggests that Siglec-15 is a potential candidate for normalization cancer immunotherapy. The expressions of Siglec-15 and PD-L1 are mutually exclusive, targeting Siglec-15 may be optimum treatment on tumors for the patients that are irresponsive to anti-PD-1/PD-L1 therapy. Currently, a first-in-human phase I clinical trial is ongoing to test the effect of a humanized $\mathrm{mAb}$ (NC318) on Siglec-15 in solid tumors (NCT03665285).

\section{Antibody-Dependent Cellular Phagocytosis}

The administration of targeted antibodies to improve the phagocytosis has been an effective therapeutic strategy to enhance the antitumor immune responses of macrophages. $\mathrm{mAb}$ s bind a variety of $\mathrm{Fc} \gamma \mathrm{Rs}$ by the Fc segment and perform their effector functions, including antibodydependent cellular cytotoxicity (ADCC), antibody-dependent cellular phagocytosis (ADCP), and complementdependent cytotoxicity $[98,99]$. For instance, the Fc region of IgG1 activates the cytotoxicity of NK cells to induce ADCC by binding to Fc $\gamma$ RIII (CD16A), triggers ADCP through binding to Fc $\gamma$ RIII (CD16A), Fc $\gamma$ RII (CD32A), and Fc $\gamma \mathrm{RI}$ (CD64) on macrophages, and activates the complement cascade via binding to $\mathrm{C} 1 \mathrm{q}$, resulting in complement-dependent cytotoxicity. Enhancing the phagocytosis of TAMs as effector cells targeting tumor cells through $\mathrm{mAb}$ therapy promotes TAMs to exhibit antitumor activities in TME [100-103]. The anti$\mathrm{CD} 20 \mathrm{mAb}$ rituximab was one of the first drugs that were approved for clinical use to treat B-cell malignancies [104, 105]. Various antitumor $m A$ bs have been applied for cancer through enhancing ADCC and ADCP, such as the anti-EGFR mAbs cetuximab and panitumumab to treat head and neck cancer and metastasized colorectal carcinoma and the anti-HER-2 mAb trastuzumab to treat breast carcinoma $[106,107]$. TAM infiltration in the invasive breast carcinomas generates poor prognosis of patients, whereas patients with colorectal cancer had a better prognosis when colon carcinomas were densely infiltrated with macrophages $[108,109]$. Thus, malignancy with TAMs is not always accompanied by a poor progno-

Macrophage-Based Combination Immunotherapies sis $[6,110]$. The study found that TAMs can accelerate the proliferation of tumor cells indeed from mouse breast carcinomas in in vitro 3D assays; nonetheless, these TAMs had the ability of phagocytosis with $\mathrm{Fc} \gamma$ receptors in the presence of anti-CD142 mAbs [111]. The antiCD142 human IgG1 mAb can bind strongly to CD142 (tissue factor) expressed on the breast tumor cells and then mediate the phagocytosis of TAMs entirely through Fc-dependent killing. Also, the deficiency of TAMs in mice reduced the efficiency of anti-CD142 mAb therapy to prevent breast carcinoma outgrowth and metastases.

The mononuclear phagocytic system, as the main effector cells, can rapidly clear tumor cells in the peripheral blood and slowly clear tumor cells in lymph nodes, splenic nodules, abdominal cavity, and Payer's collective lymph nodes [112]. Depletion of B cells by anti-murine CD20 mAbs was strictly dependent on the mononuclear phagocyte network and required expression of activating $\mathrm{Fc} \gamma$ receptors. Moreover, when mice were injected with lymphoma cells after depletion of macrophages by clodronate liposomes, the therapeutic effect of mAbs was significantly reduced, while deficiency of NK cells and neutrophils in mice rarely impacts the efficacy of mAbs [113]. Activated monocytes/macrophages can produce cytokines (IL-1, IL-6, IL-12, TNF- $\alpha$, etc.), chemokines (MIP, MCP, IL-8, etc.), proteolytic enzymes, and reactive oxygen species to enhance the phagocytosis function. Mutation of anti-CD20 mAbs that did not interact with $\mathrm{C} 1 \mathrm{q}$ also has the antitumor effect, demonstrating that survival of lymphoma-bearing mice after $\mathrm{mAb}$ therapy was not dependent on complement activation, but on tumor cell elimination by macrophages via $\mathrm{Fc} \gamma$ receptormediated processes [112]. In addition, the occurrence of several hematological malignancies, including Hodgkin disease and anaplastic large cell lymphoma, is accompanied by high expression of CD30. The anti-CD30 mAb SGN-30 induces direct antitumor activity through antibody-dependent cellular phagocytosis, mediated by macrophages, to inhibit the growth of $\mathrm{CD} 30^{+}$tumor cells. Depletion of macrophages reduced survival of tumor-bearing mice treated with SGN-30; in contrast, ablation of NK cells did not significantly affect efficacy [102].

The antitumor performance of $\mathrm{mAb}$ is dependent on the recruitment and phagocytosis function of TAMs. The therapeutic effect of anti-Her $\mathrm{Ab}$ was restricted by TAMs with the M2-type function. Tumor local delivery of IL-21 can skew TAM polarization from the M2 to the M1 phenotype, which reverses immunosuppression and invokes the active antitumor potential to bridge the gap between the innate immunity and T-cell responses for tumor re- 
gression. The combination of anti-Her2/neu $\mathrm{mAb}$ and IL-21 efficiently reverses the polarization of TAMs for promoting the therapeutic effect of anti-Her2 Ab [114]. However, there is evidence suggesting that the ADCP activity of M2 macrophages is more notable than M1 macrophages in the presence of antilymphoma $\mathrm{mAb}$. M-CSF and IL-10-differentiated M2-type macrophages increased significantly the phagocytic capacity of macrophages toward rituximab-opsonized target cells [100]. M-CSF or IL-10 increases the phagocytic capacity of macrophages toward apoptotic cells or pathogens and may be related to the higher activity of M2 macrophages in scavenging debris and tissue remodeling $[115,116]$. It suggests that IL-10-derived M2c (IL-10) cells are much more phagocytic than IL-4-differentiated M2a (IL-4) cells also for Ab-opsonized target cells [117]. Thus, manipulation of TAM functional polarization may be a promising strategy for the $\mathrm{mAb}$ treatment.

\section{Targeting the Cellular Metabolism for TAM Reprogramming}

Metabolic reprogramming is an indispensable process of macrophage plasticity and polarization. Once macrophages are recruited to the TME, they are obliged to undergo metabolic adaptations to survive in the harsh tumor milieu. For instance, arginine metabolism is associated with macrophage function, which is a feature of macrophage polarization. M1 macrophages use arginine as a substrate for iNOS, converting arginine into $\mathrm{NO}$ and citrulline by iNOS. The produced NO subsequently suppresses oxidative phosphorylation (OXPHOS) through the inhibition of enzymes involved in the TCA and electron transport chain and upregulates glycolysis. Instead, M2 macrophages utilize arginine as a substrate for Arg1. The metabolism of M1 macrophages is characterized by increased glycolytic flux and reduced mitochondrial OXPHOS. In contrast, oxidative glucose metabolism (fatty acid oxidation) is the metabolic pathway favored by IL4-activated M2 macrophages. Investigating the metabolic changes between the TME and the TAMs is a key process of exploring novel therapeutic approaches, targeting the metabolic reprogramming of macrophages to enhance the phagocytosis of the innate immune cells.

\section{Glucose Metabolism of the TAMs}

The stimulation of TLR 4 by LPS induces macrophage polarization to the M1 type, switching its major glucose metabolism pathway from OXPHOS to glycolysis. Be- sides, macrophages can also be induced to express hypoxia-inducible factor $1 \alpha$ (HIF-1 $\alpha$ ), initiating the glycolysis process to produce ATP. HIF-1 a can promote the expression of proinflammatory genes in macrophages and enhance phagocytosis. Deletion of HIF-1 $\alpha$ attenuates the ability of phagocytosis and proinflammatory cytokine secretion of macrophages [118]. HIF-1 $\alpha$ contributes to the synthesis of iNOS and the enhancement of other hypoxia element-dependent enzyme transcriptional activity under LPS stimulation or hypoxia [119]. Chelidonic acid in M1 macrophages can bind to propyl hydroxylase to inhibit the dehydrogenation and degradation of HIF-1 $\alpha$, and exogenous succinic acid can promote the stable expression of HIF-1 $\alpha$ and enhance the glycolytic metabolism of macrophages [120].

Hypoxic TAMs acquire angiogenic and immunosuppressive properties. Hypoxia is one of the major factors that determine the vascular structure of solid tumors. Hypoxia blocks the mechanistic target of rapamycin (mTOR) function through HIF-mediated transcriptional induction of the mTOR complex 1 (mTORC1) inhibitor REDD1 (regulated in development and DNA damage response 1), inhibiting glycolysis under hypoxic conditions. On the other hand, REDD1-deficient TAMs compete with adjacent endothelial cells for glucose by activating mTOR to promote the process of glycolysis, thus endowing the normalization of vascular structure and inhibiting tumor metastasis [121].

\section{Lipid Metabolism of the TAMs}

Besides glucose metabolism, the studies of lipidomics confirm that lipid metabolism is associated with functional reprogramming of TAMs [122]. Lipid metabolism can administer to the macrophage phagocytosis by regulating membrane fluidity and provide energy for the process. However, the excess absorption of cholesterol leads to abnormal cholesterol metabolism in macrophages, which can induce a series of pathological changes. Plenitudinous endoplasmic reticulum membrane and free cholesterol promote the esterification reaction of cholesterol acyltransferase 1 (ACAT1), which in turn leads to more free cholesterol production and increases inflammatory signals through lipid rafts, especially TLR and NF- $\kappa B$ signals [123-125]. The levels of fatty acid absorption and fatty acid oxidation increased significantly in IL4-stimulated M2 macrophages and were inhibited in M1 macrophages. Peroxisome proliferator-activated receptor (PPAR) is a ligand-dependent transcript that acts as a fatty acid receptor to regulate glucose and lipid metabolism. It can be divided into PPAR $\alpha$, PPAR $\delta$, and PPAR $\gamma$ 
subpopulations in which PPAR $\alpha / \operatorname{PAAR} \gamma$ is widely expressed in human and mouse monocytes, inhibiting the expression of proinflammatory genes in macrophages. PPAR $\gamma$ promotes fatty acid $\beta$-oxidation and mitochondrial production at the gene transcription level to induce the polarization of $\mathrm{M} 2$ macrophage. PGC- $1 \beta$ is a PPAR transcriptional costimulatory factor that increases the expression of genes associated with fatty acid oxidation and promotes OXPHOS in cells. Conditional knockdown of PGC-1 $\beta$ genes inhibits intracellular OXPHOS levels as well as M2 macrophage functions and greatly facilitates the proinflammatory responses of LPS-activated M1 macrophages [126].

Two recent studies also showed lipid accumulation in TAMs led to macrophage activation toward an M2-like phenotype. Deficiency of monoacylglycerol lipase (MGLL) results in lipid overload in TAMs. MGLL knockout in macrophages attenuated IL- $1 \beta$ and TNF- $\alpha$ mRNA expression in response to IFN- $\gamma$ and LPS stimulation and potentiated the expression of IL-10, Arg- 1 , and TGF- $\beta$ in response to IL-4 treatment in BMDMs. MGLL inhibits CB2 cannabinoid receptor-dependent tumor proliferation, and also MGLL deficiency promotes CB2/TLR4-dependent macrophage activation, which further suppresses the function of tumor-associated $\mathrm{CD}^{+} \mathrm{T}$ cells. Xiang et al. [127] utilize MGLL as a switch for CB2/TLR4-dependent macrophage activation to provide potential targets for cancer therapies. They screened the triglyceride metabolism-associated enzymes in TAMs and found that the expression of abhydrolase domain containing 5 (ABHD5), an activator of triglyceride hydrolysis, is lower in migratory TAMs than in the nonmigratory TAMs. ABHD5 deficiency in macrophages results in lipid accumulation and promoted NF- $\kappa \mathrm{B}$ p65-dependent production of matrix metalloproteinases. Thus, the outcomes showed that macrophage ABHD5 inhibits matrix metalloproteinase-dependent cancer cell migration $[127,128]$.

\section{Combination of Antibodies and Agonists to Reprogram TAMs}

The single treatment of targeting to the phagocytosis checkpoints can block inhibitory receptor signaling on TAMs and promote phagocytosis effectively, but not completely nor universally. The patients who are irresponsive with single immunotherapy agents or resistant to the treatments are still inappropriate with the application of ICIs in the clinical treatment. The combined application of phagocytosis checkpoint inhibitors and repo-

Macrophage-Based Combination Immunotherapies larization agents can promote TAMs as M1 macrophages with antitumor function, which is more effective than the single strategy for reeducating macrophages.

\section{CD40/CD40L}

CD40 is a highly conserved costimulatory receptor, mainly expressed on antigen-presenting cells, such as DCs, macrophages, and other monocytic system cells. CD40L as the ligand of CD40 is mainly expressed on activated $\mathrm{T}$ and $\mathrm{B}$ cells. Activation of CD40 can stimulate the activity of antigen-presenting cells, thus further activate the function of cytotoxic T cells to tumors and reverse the immunosuppression microenvironment ultimately. CD40 agonists can enhance the antitumor effects of other immunomodulators such as TLR agonists, cytokines (IFN and IL-2), adoptive immunotherapy, and chemotherapy [129]. It was found that the combination of CSF-1R blocker and CD40 agonist can significantly improve the antitumor ability and survival rate in the mouse. The Ly-6C ${ }^{\text {low }}$ $4 / 80^{+}$TAMs in the TME decreased significantly, while the remaining macrophage phenotype changed from MHC-II ${ }^{\text {low }}$ to MHC-II ${ }^{\text {high }}$, which is the proinflammatory macrophage phenotype, and the expression of costimulatory molecule CD80 and CD86 increased. The combination therapy confirmed the importance of removing the inhibitory cell population and activating the surface activation signal of immune cells [130].

ADC-1013 is a highly specific humanized IgG1 antibody designed for tumor immunity, and it targets the costimulatory receptor CD40 expressed on the surface of antigen-presenting cells. ADC- 1013 can activate CD40 of DC cells and further activate $T$ cells to enhance the immune system's ability to eliminate tumors. ADC-1013 in combination with PD-1 inhibitors had a synergistic antitumor effect in bladder cancer models [131]. At present, in addition to ADC-1013, a variety of CD40 agonists have been applied in clinical trials. Selicrelumab is a humanized IgG1 agonist of CD40, which promotes T cell-driven tumor killing by activating CD40 on antigen-presenting cells $[132,133]$. ABBV-428 is a bispecific protein therapeutic designed for mesothelin-dependent CD40 activation, which has been studied in phase I clinical trial of solid tumors [134]. APX005M has the potential to become the best-in-class CD40 agonist antibody, which can be used as a single agent or combined with other immuno-oncology drugs, targeted therapy drugs, chemotherapy, vaccines, and radiation therapy. APX005M is entering phase clinical II trials. The agonistic anti-CD40 antibody CP-870,893was tested in an escalating phase I study and 
has been well tolerated, resulting in antitumor activity [135]. RO7009789, another CD40 agonist, is currently being investigated in 4 combinatorial clinical trials in advanced stage solid tumors(NCT02760797, NCT02304393, NCT02665416, and NCT025843).

\section{Targeting the TLR for TAM Reprogramming}

TLRs are a class of pattern recognition receptors that improve immune system function through multiple signaling, activating NF- $\kappa \mathrm{B}$ signaling pathways and regulating the secretion of multiple cytokines such as TNF- $\alpha$, ILs, and IFN- $\alpha$. Imiquimod (INN) as the first TLR-targeting agonist is one of the most successful TLR-targeting drugs for various skin tumors. INN induces IFN- $\alpha$, IL-6, and TNF- $\alpha$ secretion through the TLR7-MyD88 signaling pathway and improves adaptive immune activity by adjusting innate immune function [136]. The clinical outcome shows that the combination of TLR agonists and other immunotherapy can greatly improve the therapeutic effect on tumors. In 2018, researchers developed a novel therapy strategy - a combination of TLR9 agonists (SD101), anti-OX40 antibodies, and radiotherapy effectively eliminates all cancer traces in mice, even untreated metastatic lesions at the distal end [137]. The TLR-9 agonist has been studied in situ immunotherapy for lymphoma and combination with PD-1 antibodies for melanoma in clinical trials. Clinical trials showed that 29 assessable patients had no treatment-related grade 4 or severe adverse events after receiving the combination treatment; for the most part, the tumors were reduced substantially. The tumors in untreated sites of 24 patients significantly reduced, 5 of which obtained partial remission and 1 patient with complete remission. $\mathrm{CD}^{+}$and $\mathrm{CD}^{+}{ }^{+} \mathrm{T}$ cells in TMEs increased, while follicular helper $\mathrm{T}$ cells and regulatory $\mathrm{T}$ cells (Treg) decreased [138]. In the same year, another TLR9 agonist, CMP-001, was developed and obtained the exciting phase I clinical data. CMP-001 combined with PD-1 antibodies was effective in treating patients with PD-1 ineffectiveness or drug resistance by up to $22 \%$, and tumors had completely disappeared in some of them. This treatment has truly reversed cold and hot tumors and assaulted the PD-1/L1 antibody resistance freak circle [139].

TLRs, such as TLR3 (e.g., dsRNA, poly(I:C)), TLR4 (e.g., picibanil, LPS), TLR7 (e.g., imiquimod), TLR7/8 (e.g., R848), and TLR9 (e.g., CpG-oligonucleotide), were investigated for targeting innate immune responses against cancer [140-142]. Diversified TLR agonists have been tested in vivo and are being investigated in early clinical trials to assess the safety and efficacy of cancer patients, most frequently in combination with conventional or target thera- pies. Maeda et al. [143] used 2 immunostimulatory compounds: the TLR7 agonist Imiquimod (IMQ) and the TLR3 agonist poly(I:C) to investigate the repolarizing ability in TAMs. It is known that the 2 compounds induce repolarization of TAMs through distinct signaling pathways: IMQ-TLR7 triggers NF- $\mathrm{BB}$ via the adaptor protein MyD88, resulting in the activation of an inflammatory cascade, while poly(I:C)-TLR3 signals through the TIR-domaincontaining adaptor protein, leading to IFN type I production and its target genes. The cytotoxicity assay presented that poly(I:C), but not IMQ, was effective in triggering the cytotoxic activity of tumor-conditioned macrophages against cancer cells. The outcomes revealed that poly(I:C) stimulation of tumor-conditioned macrophages is more effective than IMQ in terms of macrophage reeducation toward antitumor effectors [143].

\section{Other Strategies to Reprogram TAMs}

\section{Histone Acetylase/Histone Deacetylase}

Histone acetylase and histone deacetylase (HDAC) are enzymes that regulate chromatin structure. Acetylation of core histone proteins with endogenous HAT activity leads the chromatin helicogenic transcription factor and RNA polymerase II to bind to DNA to facilitate gene transcription. Whereas deacetylation of core histones is usually associated with transcriptional inhibition, in brief, HDAC can inhibit histone acetylation. HDAC transfers acetyl groups from histone lysine residues, causing DNA entanglement and hindering the entry of basic transcription unit protein complexes into promoter binding sites, resulting in inhibition of transcriptional function. HDAC plays an important role in inhibiting gene expression and overacetylation of core histones. In the TME, cancer cells exploit class IIA HDAC to regulate macrophage proliferation and differentiation. Typically, this enzyme puts macrophages on a "bad path" that favors tumor cell growth. The application of HDAC inhibitors is an impactful strategy to stimulate the antitumor ability of macrophages. In a mouse model of breast cancer, TMP195, as an inhibitor of Class IIA HDAC, reduced the tumor size and prevented lung metastasis, enhancing the phagocytosis of macrophages [144]. TMP195 improves the corresponding efficacy and tolerance when combined with chemotherapeutic agents or anti-PD-1 antibodies. Back in 2013, researchers found that TMP195 was able to reeducate macrophages in vitro, transforming them from "rebels" who promote tumor growth to "undercover" that could attack tumor tissues [145]. 


\section{PI3Ky Signaling Pathway}

The PI3K $\gamma$ signaling in macrophages can control the conversion of immunosuppression and immune activation. The researchers confirmed that the overexpression of macrophage-specific $\mathrm{PI} 3 \mathrm{~K} \gamma$ signaling pathway promotes tumor growth, and then knocking out the PI3K $\gamma$ gene or using the PI3K $\gamma$ inhibitor TG100-115 significantly inhibited tumor growth in mice with lung, head, and neck squamous cell carcinoma. In the process, the number of macrophages at the tumor site did not decrease, but the secretion of immunosuppressive factors had been decreased. Inhibition of the PI $3 \mathrm{~K} \gamma$ signaling pathway can also promote $\mathrm{CD} 8^{+} \mathrm{T}$-cell migration to the tumor site and enhance the cytotoxic function of T cells [146]. The continuously increased expression of PD1 and CTLA-4 in T cells of tumor site in immunosuppressive environment induces that the long-term use of PD1 and CTLA-4 inhibitors will develop drug resistance and the number of inhibitory bone marrow cells is significantly increased. The combination of PI3K $\gamma$ inhibitor IPI-549 and PD1 or CTLA-4 inhibitor significantly improved the antitumor effect [147].

\section{Macrophage-Based Cell Therapies: Genetically Engineered Macrophages}

In addition to immunotherapeutic strategies focusing on reeducating immunosuppressive TAMs or enhancing macrophage phagocytosis, another potential immunotherapeutic approach associated with macrophages is the application of genetic engineering to augment existing macrophage behaviors or endow new functionalities [19]. In brief, the primary macrophages were cultured in vitro, and then the modified macrophages as effector cells were transfused to the patients to reshape the positive TME. Back in 1990, the first clinical phase I study of adoptive immunotherapy in cancer patients using monocyte-derived macrophages as effector cells was reported. The clinical outcome shows that adoptive macrophage transfer was well tolerated and mild side effects were observed after i.p. application [148]. The failure of early trials might have been due to lack of macrophages trafficking into the tumor or to the plasticity of macrophages, resulting in a rapid loss of the antitumor phenotype.

Genetic engineering methods using exogenous macrophages instead of endogenous macrophages can be used to enforce specific therapeutic behaviors. For instance, CD47 antibodies can block the "don't eat me" signal from tumor cells while also rapidly eliminate blood cells in the blood circulation; in addition to causing anemia, it can also lead to more serious autoimmune diseases. Researchers obtained "young and robust" macrophages from the bone marrow of healthy donors and engineered them using blocking the expression of SIRPa on the cell surface and loading them with human immunoglobulin G, the most important antibody component in the serum, which could enhance the phagocytosis of macrophages [27]. In the course of treatments, the levels of red blood cells, white blood cells, platelets, and hemoglobin in mice were kept within the normal range, and there were no serious side effects in mice. The engineered macrophages can specifically accumulate in tumor tissues and devour tumors.

Because the collagen density is relatively large in the TME, the solid tumor tissue shows a "hard" state, which will change the cell phenotype and affect the phagocytosis of macrophages [149-151]. The modified macrophages can be transformed passively to the nonphagocytic state with high expression of SIRPa after surviving around the TME in a period [27]. Therefore, how to delay the rate of assimilation of modified macrophages as much as possible is the key to remodeling adoptive macrophages. Another promising strategy of modifying macrophages is constructing macrophages with chimeric antigen receptors (CAR), which probably is more effective than CAR-T in the treatment of solid tumors. A family of chimeric antigen receptors for phagocytosis (CAR-Ps) was developed to promote macrophages to engulf cancer cells. CAR-Ps consist of an extracellular antibody fragment, which can be engineered to direct CAR-P activity toward specific antigens, giving macrophages antigen-dependent phagocytosis. By screening a panel of engulfment receptor intracellular domains, the study found that the cytosolic domains Megf10 and FcR $\gamma$ robustly triggered engulfment independently of their native extracellular domain. CAR-P macrophages can reduce cancer cell numbers in an in vitro coculture system by over $40 \%$ [21].

CAR-T therapy has been a powerful strategy for blood cancers but has confronted straitened circumstances in targeting solid tumors. Lately, researchers adopt a macrophage-based immunotherapeutic approach that engineered primary human macrophages as a therapy for solid tumors. Unlike the therapeutic approaches for depleting, repolarizing, or derepressing the phagocytic activity of TAMs, macrophages as effectors and regulators of the innate immune system possess the ability of phagocytosis, cellular cytotoxicity, secretion of proinflammatory factors, and antigen presentation to T cells. Researchers transduced the human primary macrophages with an an- 
Fig. 5. CAR-modified iPSC-derived immune cells. CAR-modified iPSC-derived cells are an excellent platform for engineering-friendly and expandable immune cells for cancer immunotherapies. CAR, chimeric antigen receptors; NK, natural killer.

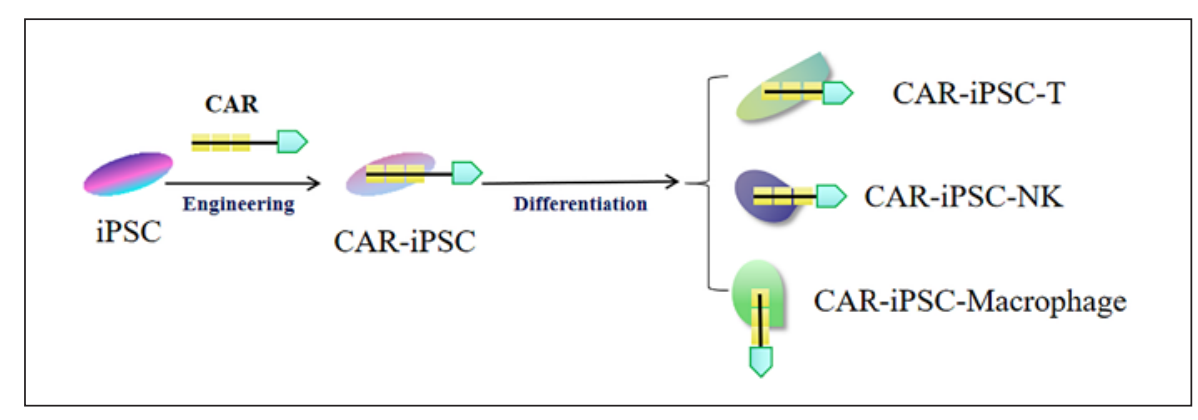

ti-HER2 CAR and measured the phagocytic potential of macrophages. CAR macrophages (CAR-Ms) were capable of antigen-specific phagocytosis in vitro and decreased tumor burden and prolonged overall survival in the solid tumor xenograft mouse models. They also evaluated the effect of CAR-Ms on M2 macrophages in vitro in virtue of proinflammatory cytokines' and chemokines' expression of CAR-Ms and found that CAR-Ms can induce a phenotypic shift in M2 macrophages to M1-type and active $\mathrm{T}$ cells as professional antigen-presenting cells and resist the effects of immunosuppressive cytokines. It shows that genetically engineering macrophages could be the key to develop cellular therapies that effectively target solid tumors [152].

Genetically engineered primary immunocytes such as T lymphocytes, NK cells, and macrophages expressing CARs provide a promising means for gene modification to enhance antitumor properties. However, here are a few outstanding challenges for efficiently engineering primary immune cells, including low transduction efficiency, highly heterogeneous genetic outcomes upon editing the genome of the targeted cells, and limited primary cell sources. Besides, immortalized primary immune cell lines do not apply to clinical settings, thus leaving iPSCderived immune cells as a great source for cell-based immunotherapy. iPSC-derived immune cells, due to their flexibility of expansion and genome editing at the iPSC stage, in theory, have advantages in dealing with the challenges above and have been proved to be effective in treating B cell cancer cells and ovarian cancer cells in preclinical settings such as iPSC-differentiated CAR-T cells [153] and CAR-NK cells [154]. CAR-Ms can specifically "eat" tumor cells or alter the TME, in an antigen-dependent way, providing a tool for direct phagocytosis or modulating a specific niche at the interface of tumor and immune cells. CAR-modified iPSC-derived myeloid cells may offer a novel source of off-the-shelf macrophages with antigen-specific phagocytosis, and they can also be produced on a large scale as a standardized cell product.
Thus, the iPSC-differentiated CAR-M is an excellent platform for engineering-friendly and expandable macrophage cells, and it is a valuable addition to other iPSCdifferentiated immune cells for further cancer immunotherapies (shown in Fig. 5).

\section{Conclusion}

Mainstream cancer immunotherapies focus on improving the immune activation through adaptive immune systems against tumors, losing sight of the innate immune system as the powerful weapon against cancer cells. Macrophages as innate immune cells have strong phagocytosis capacity against tumor cells, and they are potent antigen-presenting cells that can activate the immune system by stimulating $\mathrm{T}$ cells to exert cytotoxic function. Nevertheless, most of the macrophages tend to boost the proliferation of tumor cells rather than phagocytose tumor cells. In recent years, it has emerged that macrophages can still be recreated as innate immune cells with antitumor activity instead of inhibiting tumor growth by destroying macrophages around tumor tissues. Restoring antitumor functions of macrophages is more meaningful than simply eliminating them to inhibit tumor growth. The phagocytosis and subsequent immune recognition have been increasingly recognized to be governed by multiple inhibitory and stimulatory signals that should be considered to generate optimal antitumor responses. Tumor cells tend to inhibit the functions of macrophages by expressing a variety of immunomodulatory molecules. Therefore, the discovery and application of immune checkpoints are essential to reshape macrophage functions. The CD47-SIRP $\alpha$ axis was the first phagocytosis checkpoint discovered in cancer, and more novel phagocytosis checkpoints have since been identified.

At present, a variety of inhibitors that block the immune checkpoint signaling pathway have been applied in 
clinical treatments. Besides current macrophage-based immunotherapeutic approaches, another strategy concentrating on the combination therapy of immunocytes and immune checkpoints may greatly improve the antitumor effect. Independent treatment with adoptive cells is unable to prevent the occurrence of immune escape effect of tumor cells through the mechanism of immune checkpoints. As expected, the application of ICIs alone can interfere with the immunosuppression status of the TME partially and passively. For instance, compared with CAR-T therapy alone or the application of anti-PD-1 antibodies simply, the combination treatment of CAR-T and inhibitors for immune checkpoint can strengthen the antitumor effect substantially [155-160] (shown in Fig. 1).

Therefore, besides the TAMs-based immunotherapeutic approaches to repolarize TAMs to M1-like phenotype, we should attend to concentrate on macrophagebased cell therapies through genetically engineering macrophages ex vivo to improve the phagocytosis of macrophages and activate the tumor immune microenvironment by a large margin. Currently, research on genetic modification of macrophages is on the rise, and a handful of studies on the combination of macrophages as therapeutic cells and ICIs are being explored for oncotherapy.

The road of the combined therapy of reeducated TAM and engineered macrophages-based cell therapy ex vivo for oncotherapy is still long and winding. First, due to the presence of tumor heterogeneity, the current clinical application of the "do not eat me" signal is not competent to cope with most tumor cells. More immune checkpoint signals should be developed for different types of tumors. A deeper understanding of the mechanisms that govern the potential synergy between cytotoxic agents and phagocytosis checkpoint blockers will offer key insights required for the development of effective combination regimens for cancer treatment. Second, for the engineered macrophages, primary monocytes or macrophages from patients may not sufficient for preclinical study and clinical application. Also, how to increase the efficiency of gene editing for endowing macrophages with the stronger phagocytosis or other capability is crucial for macrophages-based adoptive immunotherapy. Controlling the macrophages may bring us closer to achieving the original goals of curing cancer, but in the journey, we still have a lot of straits to confront.

\section{Conflict of Interest Statement}

J.Z. is the scientific co-founder of CellOrigin Inc. J.Z., L.T., and A.L. hold patents related to iPSC-derived CAR-M.

\section{Funding Sources}

J.Z. is supported by the National Natural Science Foundation projects of China (31871453 and 91857116).

\section{Author Contributions}

J.Z., L.T., and H.M. designed the manuscript; L.T. and A.L. wrote the manuscript and designed the figures; and T.T., M.Z., and L.Z. revised the manuscript.

\section{References}

1 Murray PJ. Macrophage polarization. Annu Rev Physiol. 2017;79:541-66.

2 Vogelpoel LT, Hansen IS, Rispens T, Muller FJ, van Capel TM, Turina MC, et al. Fc gamma receptor-TLR cross-talk elicits pro-inflammatory cytokine production by human M2 macrophages. Nat Commun. 2014;5: 5444.

3 Zhou L, Cao X, Fang J, Li Y, Fan M. Macrophages polarization is mediated by the combination of PRR ligands and distinct inflammatory cytokines. Int J Clin Exp Pathol. 2015; 8(9):10964-74.

4 Ostuni R, Kratochvill F, Murray PJ, Natoli G. Macrophages and cancer: from mechanisms to therapeutic implications. Trends Immunol. 2015;36(4):229-39.

5 Hamm A, Prenen H, Van Delm W, Di Matteo M, Wenes M, Delamarre E, et al. Tumour-ed- ucated circulating monocytes are powerful candidate biomarkers for diagnosis and disease follow-up of colorectal cancer. Gut. 2016; 65(6):990-1000.

6 Lewis CE, Pollard JW. Distinct role of macrophages in different tumor microenvironments. Cancer Res. 2006;66(2):605-12.

7 Chávez-Galán L, Olleros ML, Vesin D, Garcia I. Much more than M1 and M2 macrophages, there are also CD169+ and TCR+ macrophages. Front Immunol. 2015 May 26;6:623.

8 Caras I, Tucureanu C, Lerescu L, Pitica R, Melinceanu L, Neagu S, et al. Influence of tumor cell culture supernatants on macrophage functional polarization: in vitro models of macrophage-tumor environment interaction. Tumori. 2011;97(5):647-54.

9 Hattermann K, Sebens S, Helm O, Schmitt $\mathrm{AD}$, Mentlein R, Mehdorn HM, et al. Chemo- kine expression profile of freshly isolated human glioblastoma-associated macrophages/ microglia. Oncol Rep. 2014;32(1):270-6.

10 Hodi FS, O'Day SJ, McDermott DF, Weber RW, Sosman JA, Haanen JB, et al. Improved survival with ipilimumab in patients with metastatic melanoma. N Engl J Med. 2010; 363(8):711-23.

11 Morris VK, Salem ME, Nimeiri H, Iqbal S, Singh P, Ciombor K, et al. Nivolumab for previously treated unresectable metastatic anal cancer (NCI9673): a multicentre, single-arm, phase 2 study. Lancet Oncol. 2017;18(4):44653.

12 Topalian SL, Hodi FS, Brahmer JR, Gettinger SN, Smith DC, McDermott DF, et al. Safety, activity, and immune correlates of anti-PD-1 antibody in cancer. N Engl J Med. 2012; 366(26):2443-54. 
13 Carbone DP, Reck M, Paz-Ares L, Creelan B, Horn L, Steins M, et al. First-line nivolumab in stage IV or recurrent non-small-cell lung cancer. N Engl J Med. 2017;376(25):2415-26.

14 Xu F, Jin T, Zhu Y, Dai C. Immune checkpoint therapy in liver cancer. J Exp Clin Cancer Res. 2018;37(1):110.

15 Su S, Zhao J, Xing Y, Zhang X, Liu J, Ouyang $Q$, et al. Immune checkpoint inhibition overcomes ADCP-induced immunosuppression by macrophages. Cell. 2018;175(2):442-57. e23.

16 Reck M, Rodríguez-Abreu D, Robinson AG Hui R, Csőszi T, Fülöp A, et al. Pembrolizumab versus chemotherapy for PD-L1-positive non-small-cell lung cancer. N Engl J Med. 2016;375(19):1823-33.

17 von Roemeling CA, Wang Y, Qie Y, Yuan H Zhao H, Liu X, et al. Therapeutic modulation of phagocytosis in glioblastoma can activate both innate and adaptive antitumour immunity. Nat Commun. 2020;11(1):1508.

18 Klichinsky M, Ruella M, Shestova O, Lu XM, Best A, Zeeman M, et al. Human chimeric antigen receptor macrophages for cancer immunotherapy. Nat Biotechnol. 2020;38(8):94753.

19 Burke B, Sumner S, Maitland N, Lewis CE Macrophages in gene therapy: cellular delivery vehicles and in vivo targets. J Leukoc Biol. 2002;72(3):417-28.

20 Koba C, Haruta M, Matsunaga Y, Matsumura K, Haga E, Sasaki Y, et al. Therapeutic effect of human iPS-cell-derived myeloid cells expressing IFN- $\beta$ against peritoneally disseminated cancer in xenograft models. PLoS One. 2013;8(6):e67567.

21 Morrissey MA, Williamson AP, Steinbach AM, Roberts EW, Kern N, Headley MB, et al. Chimeric antigen receptors that trigger phagocytosis. eLife. 2018;7:e36688.

22 Kan O, Day D, Iqball S, Burke F, Grimshaw MJ, Naylor S, et al. Genetically modified macrophages expressing hypoxia regulated cytochrome $\mathrm{P} 450$ and $\mathrm{P} 450$ reductase for the treatment of cancer. Int J Mol Med. 2011; 27(2):173-80

23 Herold J, Pipp F, Fernandez B, Xing Z, Heil $\mathrm{M}$, Tillmanns $\mathrm{H}$, et al. Transplantation of monocytes: a novel strategy for in vivo augmentation of collateral vessel growth. Hum Gene Ther. 2004;15(1):1-12.

24 Klichinsky M, Ruella M, Shestova O, Lu XM, Best A, Zeeman M, et al. Human chimeric antigen receptor macrophages for cancer immunotherapy. Nat Biotechnol. 2020 Aug;38(8): 947-53.

25 Zhang L, Tian L, Dai X, Yu H, Wang J, Lei A, et al. Pluripotent stem cell-derived CAR-macrophage cells with antigen-dependent anticancer cell functions. J Hematol Oncol. 2020 13(1):153.

26 Andreesen R, Scheibenbogen C, Brugger W, Krause S, Meerpohl HG, Leser HG, et al Adoptive transfer of tumor cytotoxic macrophages generated in vitro from circulating blood monocytes: a new approach to cancer immunotherapy. Cancer Res. 1990;50(23): 7450-6.

27 Alvey CM, Spinler KR, Irianto J, Pfeifer CR, Hayes B, Xia Y, et al. SIRPA-inhibited, marrow-derived macrophages engorge, accumulate, and differentiate in antibody-targeted regression of solid tumors. Curr Biol. 2017; 27(14):2065-77.e6

28 Ruffell B, Affara NI, Coussens LM. Differential macrophage programming in the tumor microenvironment. Trends Immunol. 2012; 33(3):119-26

29 Squadrito ML, De Palma M. Macrophage regulation of tumor angiogenesis: implications for cancer therapy. Mol Aspects Med. 2011; 32(2):123-45.

30 Mosser DM, Edwards JP. Exploring the full spectrum of macrophage activation. Nat Rev Immunol. 2008;8(12):958-69.

31 Wynn TA, Chawla A, Pollard JW. Macrophage biology in development, homeostasis and disease. Nature. 2013;496(7446):445-55.

32 McClean CM, Tobin DM. Macrophage form, function, and phenotype in mycobacterial infection: lessons from tuberculosis and other diseases. Pathog Dis. 2016;74(7):ftw068.

33 Stout RD, Jiang C, Matta B, Tietzel I, Watkins SK, Suttles J. Macrophages sequentially change their functional phenotype in response to changes in microenvironmental influences. J Immunol. 2005;175(1):342-9.

34 Biswas SK, Mantovani A. Macrophage plasticity and interaction with lymphocyte subsets: cancer as a paradigm. Nat Immunol. 2010;11(10):889-96

35 Murray PJ, Allen JE, Biswas SK, Fisher EA, Gilroy DW, Goerdt S, et al. Macrophage activation and polarization: nomenclature and experimental guidelines. Immunity. 2014; 41(1):14-20.

36 Gordon S, Taylor PR. Monocyte and macrophage heterogeneity. Nat Rev Immunol. 2005; 5(12):953-64.

37 Mantovani A, Sica A, Sozzani S, Allavena P, Vecchi A, Locati M. The chemokine system in diverse forms of macrophage activation and polarization. Trends Immunol. 2004;25(12):677-86.

38 Mantovani A, Sozzani S, Locati M, Allavena P, Sica A. Macrophage polarization: tumorassociated macrophages as a paradigm for polarized M2 mononuclear phagocytes. Trends Immunol. 2002;23(11):549-55.

39 Lahmar Q, Keirsse J, Laoui D, Movahedi K, Van Overmeire E, Van Ginderachter JA. Tissue-resident versus monocyte-derived macrophages in the tumor microenvironment. Biochim Biophys Acta. 2016;1865(1):23-34.

40 Franklin RA, Liao W, Sarkar A, Kim MV, Bivona MR, Liu K, et al. The cellular and molecular origin of tumor-associated macrophages. Science. 2014;344(6186):921-5.

41 Comito G, Giannoni E, Segura CP, Barcellosde-Souza P, Raspollini MR, Baroni G, et al. Cancer-associated fibroblasts and M2-polarized macrophages synergize during prostate carcinoma progression. Oncogene. 2014; 33(19):2423-31.
42 Orimo A, Gupta PB, Sgroi DC, ArenzanaSeisdedos F, Delaunay T, Naeem R, et al. Stromal fibroblasts present in invasive human breast carcinomas promote tumor growth and angiogenesis through elevated SDF-1/ CXCL12 secretion. Cell. 2005;121(3):335-48.

43 Haque A, Moriyama M, Kubota K, Ishiguro N, Sakamoto M, Chinju A, et al. CD206(+) tumor-associated macrophages promote proliferation and invasion in oral squamous cell carcinoma via EGF production. Sci Rep. 2019; 9(1):14611.

44 Lai YS, Wahyuningtyas R, Aui SP, Chang KT Autocrine VEGF signalling on M2 macrophages regulates $\mathrm{PD}-\mathrm{L} 1$ expression for immunomodulation of $\mathrm{T}$ cells. J Cell Mol Med. 2019;23(2):1257-67.

45 Condeelis J, Pollard JW. Macrophages: obligate partners for tumor cell migration, invasion, and metastasis. Cell. 2006;124(2):263-6.

46 Bergers G, Brekken R, McMahon G, Vu TH, Itoh T, Tamaki K, et al. Matrix metalloproteinase- 9 triggers the angiogenic switch during carcinogenesis. Nat Cell Biol. 2000;2(10): 737-44.

47 Deryugina EI, Quigley JP. Tumor angiogenesis: MMP-mediated induction of intravasation- and metastasis-sustaining neovasculature. Matrix Biol. 2015;44-46:94-112.

48 Mazzieri R, Pucci F, Moi D, Zonari E, Ranghetti A, Berti A, et al. Targeting the ANG2/ TIE2 axis inhibits tumor growth and metastasis by impairing angiogenesis and disabling rebounds of proangiogenic myeloid cells. Cancer Cell. 2011;19(4):512-26.

49 De Palma M, Naldini L. Angiopoietin-2 TIEs up macrophages in tumor angiogenesis. Clin Cancer Res. 2011;17(16):5226-32.

50 Sica A, Saccani A, Bottazzi B, Polentarutti N, Vecchi A, van Damme J, et al. Autocrine production of IL-10 mediates defective IL-12 production and NF-kappa B activation in tumor-associated macrophages. J Immunol. 2000;164(2):762-7.

51 Mittal SK, Cho KJ, Ishido S, Roche PA. Interleukin 10 (IL-10)-mediated immunosuppression: MARCH-I induction regulates antigen presentation by macrophages but not dendritic cells. J Biol Chem. 2015;290(45):2715867.

52 Sanmamed MF, Chen L. A paradigm shift in cancer immunotherapy: from enhancement to normalization. Cell. 2019;176(3):677.

53 Bylicki O, Barazzutti H, Paleiron N, Margery J, Assié JB, Chouaïd C. First-line treatment of Non-Small-Cell Lung Cancer (NSCLC) with immune checkpoint inhibitors. BioDrugs. 2019;33(2):159-71.

54 Larkin J, Chiarion-Sileni V, Gonzalez R, Grob JJ, Cowey CL, Lao CD, et al. Combined nivolumab and ipilimumab or monotherapy in untreated melanoma. N Engl J Med. 2015; 373(1):23-34.

55 Li CW, Lim SO, Chung EM, Kim YS, Park $\mathrm{AH}, \mathrm{Yao}$ J, et al. Eradication of triple-negative breast cancer cells by targeting glycosylated PD-L1. Cancer Cell. 2018;33(2):187-201.e10. 
56 Stanczak MA, Siddiqui SS, Trefny MP, Thommen DS, Boligan KF, von Gunten S, et al. Selfassociated molecular patterns mediate cancer immune evasion by engaging Siglecs on $\mathrm{T}$ cells. J Clin Invest. 2018;128(11):4912-23.

57 Ren X. Immunosuppressive checkpoint $\mathrm{Si}$ glec-15: a vital new piece of the cancer immunotherapy jigsaw puzzle. Cancer Biol Med. 2019;16(2):205-10.

58 Barkal AA, Weiskopf K, Kao KS, Gordon SR, Rosental B, Yiu YY, et al. Engagement of MHC class I by the inhibitory receptor LIL$\mathrm{RB} 1$ suppresses macrophages and is a target of cancer immunotherapy. Nat Immunol. 2018;19(1):76-84.

59 Weiskopf K. Cancer immunotherapy targeting the CD47/SIRPa axis. Eur J Cancer. 2017; 76:100-9.

60 Yang X, Feng W, Wang R, Yang F, Wang L, Chen S, et al. Repolarizing heterogeneous leukemia-associated macrophages with more M1 characteristics eliminates their pro-leukemic effects. Oncoimmunology. 2018;7(4): e1412910.

61 Müller E, Christopoulos PF, Halder S, Lunde A, Beraki K, Speth M, et al. Toll-like receptor ligands and interferon- $\gamma$ synergize for induction of antitumor M1 macrophages. Front Immunol. 2017;8:1383.

62 Sica A, Larghi P, Mancino A, Rubino L, Porta C, Totaro MG, et al. Macrophage polarization in tumour progression. Semin Cancer Biol. 2008; 18(5):349-55.

63 Zhang F, Zheng J, Kang X, Deng M, Lu Z, Kim J, et al. Inhibitory leukocyte immunoglobulin-like receptors in cancer development. Sci China Life Sci. 2015;58(12):1216-25.

64 Veillette A, Chen J. SIRPa-CD47 immune checkpoint blockade in anticancer therapy. Trends Immunol. 2018;39(3):173-84.

65 Gordon SR, Maute RL, Dulken BW, Hutter G, George BM, McCracken MN, et al. PD-1 expression by tumour-associated macrophages inhibits phagocytosis and tumour immunity. Nature. 2017;545(7655):495-9.

66 Cai J, Qi Q, Qian X, Han J, Zhu X, Zhang Q, et al. The role of PD-1/PD-L1 axis and macrophage in the progression and treatment of cancer. J Cancer Res Clin Oncol. 2019;145(6): 1377-85.

67 del Rio ML, Seebach JD, Fernández-Renedo C, Rodriguez-Barbosa JI. ITIM-dependent negative signaling pathways for the control of cell-mediated xenogeneic immune responses. Xenotransplantation. 2013;20(6):397406.

68 Brooke GP, Parsons KR, Howard CJ. Cloning of two members of the SIRP alpha family of protein tyrosine phosphatase binding proteins in cattle that are expressed on monocytes and a subpopulation of dendritic cells and which mediate binding to CD4 T cells. Eur J Immunol. 1998;28(1):1-11.

69 Timms JF, Carlberg K, Gu H, Chen H, Kamatkar S, Nadler MJ, et al. Identification of major binding proteins and substrates for the $\mathrm{SH} 2$ containing protein tyrosine phosphatase
SHP-1 in macrophages. Mol Cell Biol. 1998; 18(7):3838-50.

70 Adams S, van der Laan LJ, Vernon-Wilson E, Renardel de Lavalette C, Döpp EA, Dijkstra $\mathrm{CD}$, et al. Signal-regulatory protein is selectively expressed by myeloid and neuronal cells. J Immunol. 1998;161(4):1853-9.

71 Weiskopf K, Jahchan NS, Schnorr PJ, Cristea S, Ring AM, Maute RL, et al. CD47-blocking immunotherapies stimulate macrophagemediated destruction of small-cell lung cancer. J Clin Invest. 2016;126(7):2610-20.

72 Majeti R, Chao MP, Alizadeh AA, Pang WW, Jaiswal S, Gibbs KD Jr, et al. CD47 is an adverse prognostic factor and therapeutic antibody target on human acute myeloid leukemia stem cells. Cell. 2009;138(2):286-99.

73 Chao MP, Alizadeh AA, Tang C, Myklebust JH, Varghese B, Gill S, et al. Anti-CD47 antibody synergizes with rituximab to promote phagocytosis and eradicate non-Hodgkin lymphoma. Cell. 2010;142(5):699-713.

74 Weiskopf K, Anderson KL, Ito D, Schnorr PJ Tomiyasu H, Ring AM, et al. Eradication of canine diffuse large B-cell lymphoma in a murine xenograft model with CD47 blockade and anti-CD20. Cancer Immunol Res. 2016; 4(12):1072-87.

75 Lin GHY, Chai V, Lee V, Dodge K, Truong T, Wong $\mathrm{M}$, et al. TTI-621 (SIRPalphaFc), a CD47-blocking cancer immunotherapeutic, triggers phagocytosis of lymphoma cells by multiple polarized macrophage subsets. PLoS One. 2017;12(10):e0187262.

76 Folkes AS, Feng M, Zain JM, Abdulla F, Rosen ST, Querfeld C. Targeting CD47 as a cancer therapeutic strategy: the cutaneous T-cell lymphoma experience. Curr Opin Oncol. 2018;30(5):332-7.

77 Huang Y, Ma Y, Gao P, Yao Z. Targeting CD47: the achievements and concerns of current studies on cancer immunotherapy. J Thorac Dis. 2017;9(2):E168-74.

78 Uger R, Johnson L. Blockade of the CD47SIRPalpha axis: a promising approach for cancer immunotherapy. Expert Opin Biol Ther. 2020;20(1):5-8.

79 Oldenborg PA, Zheleznyak A, Fang YF, Lagenaur CF, Gresham HD, Lindberg FP. Role of CD47 as a Marker of Self on Red Blood Cells. Science. 2000;288(5473):2051-4.

80 Advani R, Flinn I, Popplewell L, Forero A, Bartlett NL, Ghosh N, et al. CD47 blockade by Hu5F9-G4 and rituximab in non-Hodgkin's lymphoma. N Engl J Med. 2018;379(18): 1711-21.

81 Liu X, Kwon H, Li Z, Fu YX. Is CD47 an innate immune checkpoint for tumor evasion? J Hematol Oncol. 2017;10(1):12.

82 Wu Z, Weng L, Zhang T, Tian H, Fang L, Teng $\mathrm{H}$, et al. Identification of glutaminyl cyclase isoenzyme isoQC as a regulator of SIRPa-CD47 axis. Cell Res. 2019;29(6):5025.

83 Jain S, Van Scoyk A, Morgan EA, Matthews A, Stevenson K, Newton G, et al. Targeted inhibition of CD47-SIRPa requires Fc-Fc $\gamma \mathrm{R}$ in- teractions to maximize activity in T-cell lymphomas. Blood. 2019;134(17):1430-40.

84 Willingham SB, Volkmer JP, Gentles AJ, Sahoo D, Dalerba P, Mitra SS, et al. The CD47signal regulatory protein alpha (SIRPa) interaction is a therapeutic target for human solid tumors. Proc Natl Acad Sci U S A. 2012; 109(17):6662-7.

85 Nakajima H, Samaridis J, Angman L, Colonna M. Human myeloid cells express an activating ILT receptor (ILT1) that associates with $\mathrm{Fc}$ receptor gamma-chain. J Immunol. 1999;162(1):5-8.

86 Zhang Z, Hatano H, Shaw J, Olde Nordkamp M, Jiang G, Li D, et al. The leukocyte immunoglobulin-like receptor family member LILRB5 binds to HLA-class I heavy chains. PLoS One. 2015;10(6): $\mathrm{e} 0129063$.

87 Chen HM, van der Touw W, Wang YS, Kang $\mathrm{K}$, Mai S, Zhang J, et al. Blocking immunoinhibitory receptor LILRB2 reprograms tumorassociated myeloid cells and promotes antitumor immunity. J Clin Invest. 2018;128(12): 5647-62.

88 Liu Y, Dong Y, Kong L, Shi F, Zhu H, Yu J. Abscopal effect of radiotherapy combined with immune checkpoint inhibitors. J Hematol Oncol. 2018;11(1):104.

89 Hegde PS, Karanikas V, Evers S. The where, the when, and the how of immune monitoring for cancer immunotherapies in the era of checkpoint inhibition. Clin Cancer Res. 2016; 22(8):1865-74.

90 Crocker PR, Redelinghuys P. Siglecs as positive and negative regulators of the immune system. Biochem Soc Trans. 2008;36(Pt 6): 1467-71.

91 Paulson JC, Macauley MS, Kawasaki N. Siglecs as sensors of self in innate and adaptive immune responses. Ann N Y Acad Sci. 2012; 1253:37-48.

92 Campanero-Rhodes MA, Childs RA, Kiso M, Komba S, Le Narvor C, Warren J, et al. Carbohydrate microarrays reveal sulphation as a modulator of siglec binding. Biochem Biophys Res Commun. 2006;344(4):1141-6.

93 Vivier E, Daëron M. Immunoreceptor tyrosine-based inhibition motifs. Immunol Today. 1997;18(6):286-91.

94 Crocker PR, Paulson JC, Varki A. Siglecs and their roles in the immune system. Nat Rev Immunol. 2007;7(4):255-66.

95 Hamann PR, Hinman LM, Hollander I, Beyer CF, Lindh D, Holcomb R, et al. Gemtuzumab ozogamicin, a potent and selective anti-CD33 antibody-calicheamicin conjugate for treatment of acute myeloid leukemia. Bioconjug Chem. 2002;13(1):47-58.

96 Barkal AA, Brewer RE, Markovic M, Kowarsky M, Barkal SA, Zaro BW, et al. CD24 signalling through macrophage Siglec-10 is a target for cancer immunotherapy. Nature. 2019; 572:392-6.

97 Wang J, Sun J, Liu LN, Flies DB, Nie X, Toki M, et al. Siglec-15 as an immune suppressor and potential target for normalization cancer immunotherapy. Nat Med. 2019;25(4):656-66. 
98 Braster R, O'Toole T, van Egmond M. Myeloid cells as effector cells for monoclonal antibody therapy of cancer. Methods. 2014; 65(1):28-37.

99 Gul N, van Egmond M. Antibody-dependent phagocytosis of tumor cells by macrophages: a potent effector mechanism of monoclonal antibody therapy of cancer. Cancer Res. 2015;75(23):5008-13.

100 Leidi M, Gotti E, Bologna L, Miranda E, Rimoldi M, Sica A, et al. M2 macrophages phagocytose rituximab-opsonized leukemic targets more efficiently than $\mathrm{m} 1$ cells in vitro. J Immunol. 2009;182(7):4415-22.

101 Otten MA, van der Bij GJ, Verbeek SJ, Nimmerjahn F, Ravetch JV, Beelen RH, et al. Experimental antibody therapy of liver metastases reveals functional redundancy between Fc gammaRI and Fc gammaRIV. J Immunol. 2008;181(10):6829-36.

102 Oflazoglu E, Stone IJ, Gordon KA, Grewal IS, van Rooijen N, Law CL, et al. Macrophages contribute to the antitumor activity of the anti-CD30 antibody SGN-30. Blood. 2007;110(13):4370-2.

103 Fridlender ZG, Jassar A, Mishalian I, Wang LC, Kapoor V, Cheng G, et al. Using macrophage activation to augment immunotherapy of established tumours. Br J Cancer. 2013; 108(6):1288-97.

104 McLaughlin P, Grillo-López AJ, Link BK, Levy R, Czuczman MS, Williams ME, et al. Rituximab chimeric anti-CD20 monoclonal antibody therapy for relapsed indolent lymphoma: half of patients respond to a fourdose treatment program. J Clin Oncol. 1998; 16(8):2825-33.

105 Maloney DG, Liles TM, Czerwinski DK, Waldichuk C, Rosenberg J, Grillo-Lopez A, et al. Phase I clinical trial using escalating single-dose infusion of chimeric anti-CD20 monoclonal antibody (IDEC-C2B8) in patients with recurrent B-cell lymphoma. Blood. 1994;84(8):2457-66.

106 Shi Y, Fan X, Deng H, Brezski RJ, Rycyzyn $M$, Jordan RE, et al. Trastuzumab triggers phagocytic killing of high HER2 cancer cells in vitro and in vivo by interaction with $\mathrm{Fc} \gamma$ receptors on macrophages. J Immunol. 2015;194(9):4379-86.

107 Bier H, Hoffmann T, Haas I, van Lierop A. Anti-(epidermal growth factor) receptor monoclonal antibodies for the induction of antibody-dependent cell-mediated cytotoxicity against squamous cell carcinoma lines of the head and neck. Cancer Immunol Immunother. 1998;46(3):167-73.

108 Forssell J, Oberg A, Henriksson ML, Stenling R, Jung A, Palmqvist R. High macrophage infiltration along the tumor front correlates with improved survival in colon cancer. Clin Cancer Res. 2007;13(5):1472-9.

109 Zhou Q, Peng RQ, Wu XJ, Xia Q, Hou JH, Ding Y, et al. The density of macrophages in the invasive front is inversely correlated to liver metastasis in colon cancer. J Transl Med. 2010;8:13.
110 Leek RD, Lewis CE, Whitehouse R, Greenall M, Clarke J, Harris AL. Association of macrophage infiltration with angiogenesis and prognosis in invasive breast carcinoma. Cancer Res. 1996;56(20):4625-9.

111 Grugan KD, McCabe FL, Kinder M, Greenplate AR, Harman BC, Ekert JE, et al. Tumor-associated macrophages promote invasion while retaining Fc-dependent anti-tumor function. J Immunol. 2012;189(11): 5457-66.

112 Gong Q, Ou Q, Ye S, Lee WP, Cornelius J, Diehl L, et al. Importance of cellular microenvironment and circulatory dynamics in B cell immunotherapy. J Immunol. 2005; 174(2):817-26.

113 Uchida J, Hamaguchi Y, Oliver JA, Ravetch JV, Poe JC, Haas KM, et al. The innate mononuclear phagocyte network depletes $\mathrm{B}$ lymphocytes through Fc receptor-dependent mechanisms during anti-CD20 antibody immunotherapy. J Exp Med. 2004; 199(12):1659-69.

114 Xu M, Liu M, Du X, Li S, Li H, Li X, et al. Intratumoral delivery of IL-21 overcomes anti-Her2/Neu resistance through shifting tumor-associated macrophages from M2 to M1 phenotype. J Immunol. 2015;194(10): 4997-5006.

115 Verreck FAW, de Boer T, Langenberg DML, Hoeve MA, Kramer M, Vaisberg E, et al. Human IL-23-producing type 1 macrophages promote but IL-10-producing type 2, macrophages subvert, immunity to (myco)bacteria. P Natl Acad Sci USA. 2004;101(13):4560-5.

$116 \mathrm{Xu} \mathrm{W}$, Roos A, Schlagwein N, Woltman AM, Daha MR, van Kooten C. IL-10-producing macrophages preferentially clear early apoptotic cells. Blood. 2006;107(12):4930-7.

117 Ogden CA, Pound JD, Batth BK, Owens S, Johannessen I, Wood K, et al. Enhanced apoptotic cell clearance capacity and B cell survival factor production by IL-10-activated macrophages: implications for Burkitt's lymphoma. J Immunol. 2005;174(5):301523.

118 Nizet V, Johnson RS. Interdependence of hypoxic and innate immune responses. Nat Rev Immunol. 2009;9(9):609-17.

119 Mi Z, Rapisarda A, Taylor L, Brooks A, Creighton-Gutteridge M, Melillo G, et al. Synergystic induction of HIF-1alpha transcriptional activity by hypoxia and lipopolysaccharide in macrophages. Cell Cycle. 2008; 7(2):232-41.

120 Tannahill GM, Curtis AM, Adamik J, Palsson-McDermott EM, McGettrick AF, Goel $\mathrm{G}$, et al. Succinate is an inflammatory signal that induces IL-1 $\beta$ through HIF-1 $\alpha$. Nature. 2013;496(7444):238-42.

121 Wenes M, Shang M, Di Matteo M, Goveia J, Martín-Pérez R, Serneels J, et al. Macrophage metabolism controls tumor blood vessel morphogenesis and metastasis. Cell Metab. 2016;24(5):701-15.

122 Dennis EA, Deems RA, Harkewicz R, Quehenberger O, Brown HA, Milne SB, et al. A mouse macrophage lipidome. J Biol Chem. 2010;285(51):39976-85.

123 Zhu X, Owen JS, Wilson MD, Li H, Griffiths GL, Thomas MJ, et al. Macrophage ABCA1 reduces MyD88-dependent toll-like receptor trafficking to lipid rafts by reduction of lipid raft cholesterol. J Lipid Res. 2010; 51(11):3196-206

124 Mogilenko DA, Orlov SV, Trulioff AS, Ivanov AV, Nagumanov VK, Kudriavtsev IV, et al. Endogenous apolipoprotein A-I stabilizes ATP-binding cassette transporter A1 and modulates toll-like receptor 4 signaling in human macrophages. FASEB J. 2012;26(5): 2019-30.

125 Yvan-Charvet L, Welch C, Pagler TA, Ranalletta M, Lamkanfi M, Han S, et al. Increased inflammatory gene expression in $\mathrm{ABC}$ transporter-deficient macrophages: free cholesterol accumulation, increased signaling via toll-like receptors, and neutrophil infiltration of atherosclerotic lesions. Circulation. 2008;118(18):1837-47.

126 Vats D, Mukundan L, Odegaard JI, Zhang L, Smith KL, Morel CR, et al. Oxidative metabolism and PGC-1beta attenuate macrophage-mediated inflammation. Cell Metab. 2006;4(1):13-24.

127 Xiang W, Shi R, Kang X, Zhang X, Chen P, Zhang L, et al. Monoacylglycerol lipase regulates cannabinoid receptor 2-dependent macrophage activation and cancer progression. Nat Commun. 2018;9(1):2574.

128 Shang S, Ji X, Zhang L, Chen J, Li C, Shi R, et al. Macrophage ABHD5 suppresses NFkB-dependent matrix metalloproteinase expression and cancer metastasis. Cancer Res. 2019;79(21):5513-26.

129 Byrne KT, Leisenring NH, Bajor DL, Vonderheide RH. CSF-1R-dependent lethal hepatotoxicity when agonistic CD40 antibody is given before but not after chemotherapy. J Immunol. 2016;197(1):179-87.

130 Wiehagen KR, Girgis NM, Yamada DH Smith AA, Chan SR, Grewal IS, et al. Combination of CD40 agonism and CSF-1R blockade reconditions tumor-associated macrophages and drives potent antitumor immunity. Cancer Immunol Res. 2017; 5(12):1109-21.

131 Irenaeus SMM, Nielsen D, Ellmark P, Yachnin J, Deronic A, Nilsson A, et al. Firstin-human study with intratumoral administration of a CD40 agonistic antibody, ADC1013, in advanced solid malignancies. Int $J$ Cancer. 2019;145(5):1189-99.

132 Vonderheide RH, Flaherty KT, Khalil M, Stumacher MS, Bajor DL, Hutnick NA, et al. Clinical activity and immune modulation in cancer patients treated with $\mathrm{CP}-870,893$, a novel CD40 agonist monoclonal antibody. J Clin Oncol. 2007;25(7):876-83.

133 Piechutta M, Berghoff AS. New emerging targets in cancer immunotherapy: the role of Cluster of Differentiation 40 (CD40/ TNFR5). ESMO Open. 2019;4(Suppl 3): e000510. 
134 Ye S, Cohen D, Belmar NA, Choi D, Tan SS, Sho M, et al. A bispecific molecule targeting CD40 and tumor antigen mesothelin enhances tumor-specific immunity. Cancer Immunol Res. 2019;7(11):1864-75.

135 Vonderheide RH, Flaherty KT, Khalil M, Stumacher MS, Bajor DL, Hutnick NA, et al. Clinical activity and immune modulation in cancer patients treated with $\mathrm{CP}-870,893$, a novel CD40 agonist monoclonal antibody. J Clin Oncol. 2007;25(7):876-83.

136 Hemmi H, Kaisho T, Takeuchi O, Sato S, Sanjo H, Hoshino K, et al. Small anti-viral compounds activate immune cells via the TLR7 MyD88-dependent signaling pathway. Nat Immunol. 2002;3(2):196-200.

137 Frank MJ, Reagan PM, Bartlett NL, Gordon LI, Friedberg JW, Czerwinski DK, et al. In situ vaccination with a TLR9 agonist and local low-dose radiation induces systemic responses in untreated indolent lymphoma. Cancer Discov. 2018;8(10):1258-69.

138 Ribas A, Medina T, Kummar S, Amin A, Kalbasi A, Drabick JJ, et al. SD-101 in combination with pembrolizumab in advanced melanoma: results of a phase Ib, multicenter study. Cancer Discov. 2018;8(10):1250-7.

139 Zonneveld-Huijssoon E, van Wijk F, Roord S, Delemarre E, Meerding J, de Jager W, et al. TLR9 agonist CpG enhances protective nasal HSP60 peptide vaccine efficacy in experimental autoimmune arthritis. Ann Rheum Dis. 2012;71(10):1706-15.

140 Seya T, Takeda Y, Matsumoto M. A Toll-like receptor 3 (TLR3) agonist ARNAX for therapeutic immunotherapy. Adv Drug Deliv Rev. 2019;147:37-43.

141 Michaelis KA, Norgard MA, Zhu X, Levasseur PR, Sivagnanam S, Liudahl SM, et al. Publisher correction: the TLR7/8 agonist R848 remodels tumor and host responses to promote survival in pancreatic cancer. Nat Commun. 2019;10(1):5257.

142 Liu M, O’Connor RS, Trefely S, Graham K, Snyder NW, Beatty GL. Metabolic rewiring of macrophages by $\mathrm{CpG}$ potentiates clearance of cancer cells and overcomes tumorexpressed CD47-mediated "don't-eat-me" signal. Nat Immunol. 2019;20(3):265-75.
143 Maeda A, Digifico E, Andon FT, Mantovani A, Allavena P. Poly(I:C) stimulation is superior than imiquimod to induce the antitumoral functional profile of tumor-conditioned macrophages. Eur J Immunol. 2019; 49(5):801-11.

144 Guerriero JL, Sotayo A, Ponichtera HE, Castrillon JA, Pourzia AL, Schad S, et al. Class IIa HDAC inhibition reduces breast tumours and metastases through anti-tumour macrophages. Nature. 2017;543(7645):42832.

145 Lobera M, Madauss KP, Pohlhaus DT, Wright QG, Trocha M, Schmidt DR, et al. Selective class IIa histone deacetylase inhibition via a nonchelating zinc-binding group. Nat Chem Biol. 2013;9(5):319-25.

146 Kaneda MM, Messer KS, Ralainirina N, Li $\mathrm{H}$, Leem CJ, Gorjestani S, et al. PI3K $\gamma$ is a molecular switch that controls immune suppression. Nature. 2016;539(7629):437-42.

147 De Henau O, Rausch M, Winkler D, Campesato LF, Liu C, Cymerman DH, et al. Overcoming resistance to checkpoint blockade therapy by targeting PI3K $\gamma$ in myeloid cells. Nature. 2016;539(7629):443-7.

148 Fidler IJ. Inhibition of pulmonary metastasis by intravenous injection of specifically activated macrophages. Cancer Res. 1974;34(5): 1074-8.

149 Egeblad M, Rasch MG, Weaver VM. Dynamic interplay between the collagen scaffold and tumor evolution. Curr Opin Cell Biol. 2010;22(5):697-706.

150 Swift J, Ivanovska IL, Buxboim A, Harada T, Dingal PC, Pinter J, et al. Nuclear lamin-A scales with tissue stiffness and enhances matrix-directed differentiation. Science. 2013; 341(6149): 1240104

151 Patel NR, Bole M, Chen C, Hardin CC, Kho AT, Mih J, et al. Cell elasticity determines macrophage function. PLoS One. 2012;7(9): e41024.
152 Klichinsky M, Ruella M, Shestova O, Lu XM Best A, Zeeman M, et al. Human chimeric antigen receptor macrophages for cancer immunotherapy. Nature Biotechnology. 2020 Aug;38(8):947-53.

153 Themeli M, Kloss CC, Ciriello G, Fedorov VD, Perna F, Gonen M, et al. Generation of tumor-targeted human $\mathrm{T}$ lymphocytes from induced pluripotent stem cells for cancer therapy. Nat Biotechnol. 2013;31(10):92833.

154 LiY,Hermanson DL, Moriarity BS, Kaufman DS. Human iPSC-derived natural killer cells engineered with chimeric antigen receptors enhance anti-tumor activity. Cell Stem Cell. 2018;23(2):181-92.e5.

155 Serganova I, Moroz E, Cohen I, Moroz M, Mane M, Zurita J, et al. Enhancement of PSMA-directed CAR Adoptive immunotherapy by PD-1/PD-L1 blockade. Mol Ther Oncolytics. 2017;4:41-54.

156 John LB, Kershaw MH, Darcy PK. Blockade of PD-1 immunosuppression boosts CAR Tcell therapy. Oncoimmunology. 2013;2(10): e26286.

157 Gargett T, Yu W, Dotti G, Yvon ES, Christo SN, Hayball JD, et al. GD2-specific CAR T cells undergo potent activation and deletion following antigen encounter but can be protected from activation-induced cell death by PD-1 Blockade. Mol Ther. 2016;24(6):113549.

158 John LB, Devaud C, Duong CP, Yong CS Beavis PA, Haynes NM, et al. Anti-PD-1 antibody therapy potently enhances the eradication of established tumors by gene-modified T cells. Clin Cancer Res. 2013;19(20): 5636-46.

159 Chong EA, Melenhorst JJ, Lacey SF, Ambrose DE, Gonzalez V, Levine BL, et al. PD-1 blockade modulates chimeric antigen receptor (CAR)-modified $\mathrm{T}$ cells: refueling the CAR. Blood. 2017;129(8):1039-41.

160 Cherkassky L, Morello A, Villena-Vargas J, Feng Y, Dimitrov DS, Jones DR, et al. Human CAR T cells with cell-intrinsic PD-1 checkpoint blockade resist tumor-mediated inhibition. J Clin Invest. 2016;126(8):313044. 